\title{
Controls on turbidite sedimentation: Insights from a quantitative approach of submarine channel and lobe architecture (Late Quaternary Congo fan)
}

\author{
Picot Marie ${ }^{1,{ }^{*}}$, Droz Laurence ${ }^{1}$, Marsset Tania ${ }^{2}$, Dennielou Bernard ${ }^{2}$, Bez M. ${ }^{3}$ \\ ${ }^{1}$ Laboratoire Domaines Océaniques, UMR6538, Institut Universitaire Européen de la Mer, Place \\ Nicolas Copernic, 29280 Plouzané, France \\ ${ }^{2}$ Laboratoire Environnements Sédimentaires, UR GM, IFREMER, BP 70, 29280 Plouzané, France \\ ${ }^{3}$ Centre Scientifique et Technique Jean Feger, Total, Avenue Larribau, 64018 Pau, France \\ * Corresponding author: Marie Picot, Tel.: +33 (0)2 98498717 ; \\ email address : picot.marie@outlook.com \\ Laurence.Droz@univ-brest.fr ; Tania.Marsset@ifremer.fr ; Bernard.Dennielou@ifremer.fr ; \\ Martine.Bez@total.fr
}

\begin{abstract}
:
The role of internal and external forcing of sedimentation in turbidite systems remains a subject of debate. Here we propose new insights from the quantitative analysis of architectural parameters of the Congo Axial Fan.
\end{abstract}

Fifty-two channel-levee-lobe systems, spanning the last ca. $200 \mathrm{ka}$, are visible on the seafloor, most of them having slightly elongated lobe complexes at their termination. Volumes of lobe complexes (usually 3 to $196 \mathrm{~km} 3$ ) are highly variable in time and space. The cumulative volume of the lobe complexes represents approximately $30 \%$ of the volume of the Axial Fan.

The Axial Fan is sequentially divided into periods of increasing/decreasing channel lengths and basinward/landward migrations of avulsion points, representing successive prograding/retrograding architectural patterns called architectural cycles. These cycles are either symmetrical saw toothed and bell-shaped with progressive progradation and retrogradation phases, or asymmetrical, with long-lasting progradation phases and abrupt retrogradation phases that correspond to channel avulsions occurring high up on the fan.

Our study points to the interplay between internal and external factors controlling the architecture of the Congo Axial Fan. The local topographic constraint is a major factor in the fan's stacking pattern. However, cyclic evolution of the architecture reveals major shifts in the deposition site that are linked to very upfan avulsion events. These events are interpreted to be driven by external factors (e.g. climate and/or eustatic sea-level change) that were able to drastically increase and/or coarsen the sediment supply to the fan. 


\section{Highlights}

- Exhaustive architectural evolution of the Congo turbidite system since $200 \mathrm{ka}$. Shifts of channellevee-lobe systems reveal cyclic patterns at different time scales. Dimensions of terminal lobe complexes do not exhibit cyclic evolution. - Pointing to permanent internal control by inherited topography. Revealing possible exceptional periods of increased or coarsening Congo River inputs.

Keywords : Turbidite system, Congo, Late Quaternary, lobe complexes, sedimentary cycles, avulsion, bathymetry, seismic profiles

\section{Introduction}

Turbidite systems are among the biggest sedimentary systems on earth and are intensively studied because they host many major offshore oil plays discovered during the last decades but also because they play a role in climate fluctuations as they trap huge amounts of sediments and carbon. Their structure and composition are highly variable and are related to sediment source composition and the nature of the supplying system, both of which are used for classification (e.g. Reading and Richards, 1994). Turbidity currents build channellevee- lobe systems that migrate in response to channel avulsion, which is the main process governing the architecture of fans.

Factors that control the sedimentation in turbidite systems are still highly debated. Internal factors such as topographic compensation, levee aggradation, channel meandering and overcutting, and channel avulsion have all been interpreted as factors controlling the growth pattern of turbidite systems (e.g. Flood and Piper, 1997; Pirmez et al., 2000; Prélat et al., 2010, 2009).

In addition, the importance of external controls, such as eustatic and climatic fluctuations, on these sedimentary systems at different time scales has been outlined (e.g. Badalini et al., 2000; Kolla and Macurda Jr, 1988; Lopez, 2001; Manley and Flood, 1988; Payros and Martínez-Braceras, 2014; Toucanne et al., 2012). 
At a system scale, for instance on the Amazon Fan, the chrono-stratigraphic framework provided by Leg 155 ODP drillings (Flood and Piper, 1997) delivered clues that uncovered a link between sedimentation and architectural evolution to climate and eustasy. Maslin et al. (2006) assumed that channel avulsions in the Amazon Fan could be triggered by pulses of sediment flux, and therefore be externally forced by factors such as sea level and/or climate fluctuations. Lopez (2001) also suggests that sea level variations influence the occurrence of the avulsion process, which is more frequent during periods of sea level lowering. Additionally, at the levee scale it was demonstrated that external forcing mechanisms such as sediment flux pulses or sea level fluctuations control the growth of the levees (Bonneau et al., 2014; Jorry et al., 2011; Toucanne et al., 2012) therefore potentially playing a role in triggering channel avulsions and thus influencing the distribution pattern of the channel-levee-lobe systems.

The detailed morphology and structure of turbidite systems remains poorly understood as there is a limited amount of high-resolution data on modern systems. Particularly, there is a lack of integrated information on the architecture and channel-levee-lobe stacking patterns and hierarchy. Such knowledge is crucial because the channel-levee-lobe system is the elementary building block in the development of turbidite systems and as such, it is this level of detailed information that is needed about the morphology, structure, and composition to fully understand the interplay between internal and external forcing in building turbidite systems.

In this respect, this paper focuses on the detailed architecture of the Axial Fan portion of the Late Quaternary Congo turbidite system since ca. $200 \mathrm{ka}$ (Droz et al., 2003). This work is the revision of a previous work carried out on the whole Quaternary turbidite system ( 800 ka to present) by Marsset et al. (2009), based on new data acquired in 2011 (Droz and Marsset, 2011; Marsset and Droz, 2010). With this dataset we developed a new method to quantify the morpho-sedimentary complexity of turbidite systems by determining at a fan scale an exhaustive inventory of channel-levee-lobe systems as well as their detailed morphologies, emplacement, size, and volumes and the relative chronology of avulsions.

Our objective is to detail the repetitive patterns observed in the characteristics and stacking of the channellevee-lobe systems, in order to discuss the controls on the evolution of the Axial Fan. We focus particularly on the channels prograding/retrograding pattern and on the occurrence of infrequent major upfan avulsions and 
frequent minor avulsions in order to identify the role of the local topography and thus to also discuss the role of possible external control by sea level and climate.

\section{Geological setting and previous work}

The Quaternary Congo turbidite system, located on the Congo-Angola passive margin, extends westwards along $800-1000 \mathrm{~km}$ from 2000 to $5200 \mathrm{~m}$ water depth. Its minimum width is $400 \mathrm{~km}$ in the N-S direction (Fig. 1). The present mean gradient of the seabed of the Congo Fan evolves from $2-3 \%$ on the continental slope to less than $0.25 \%$ in the abyssal plain (Babonneau et al., 2002) (Fig. 1B).

The margin is affected by marked halokinetic deformation caused by diapirism of the Aptian salt deposited during the rift phase that led to the opening of the South Atlantic Ocean during the Early Cretaceous (Emery et al., 1975; Jansen, 1985; Reyre, 1984). A first deep-sea fan with a maximal thickness of approximately $2.5 \mathrm{~km}$ had formed during the Albian-Eocene ages (Anka, 2004; Anka et al., 2010), which shows that the Congo river was already a terrigenous sediment supplier. A continental uplift in the Oligocene led to an increase in erosion and river load, resulting in an increase in sediment supply to the basin. This increased sediment supply was enhanced by a decrease in global sea-level at that time and by the humid climatic conditions that prevailed in the river basin during this period (Droz et al., 1996; Reyre, 1984). These were favorable conditions for the setup of a Tertiary turbidite system (Anka, 2004; Brice et al., 1982; Karner and Driscoll, 1999). Since then, the Congo River has fed the Quaternary turbidite system.

The Congo turbidite system is one of the largest mud-rich fans in the world. It is supplied by only one point source (the Congo River) and fed by a giant watershed basin (Reading and Richards, 1994; Stow et al., 1996; Stow and Mayall, 2000) (Fig. 1). With a $4370 \mathrm{~km}$-long river which flows in a huge, low slope gradient drainage basin of $3.7 \times 10^{6} \mathrm{~km}^{2}$ (Van Weering and Van Iperen, 1984), the Congo fluvial system is the most important hydrographic network of West Africa. These characteristics, along with its high average flow (fluid discharge) of $42,800 \mathrm{~m}^{3} \mathrm{~s}^{-1}$ (Kinga-Mouzeo, 1986), rank the Congo River as the second largest river in the world after the Amazon River. In addition, the Congo Basin includes several lakes, which favor the trapping of coarse-grained 
fluvial sediments (Moguedet, 1988; Turakiewicz, 2004; Wefer et al., 1998a) (Fig. 1). These topographic conditions contribute to the mud-rich composition of the Congo turbidite system.
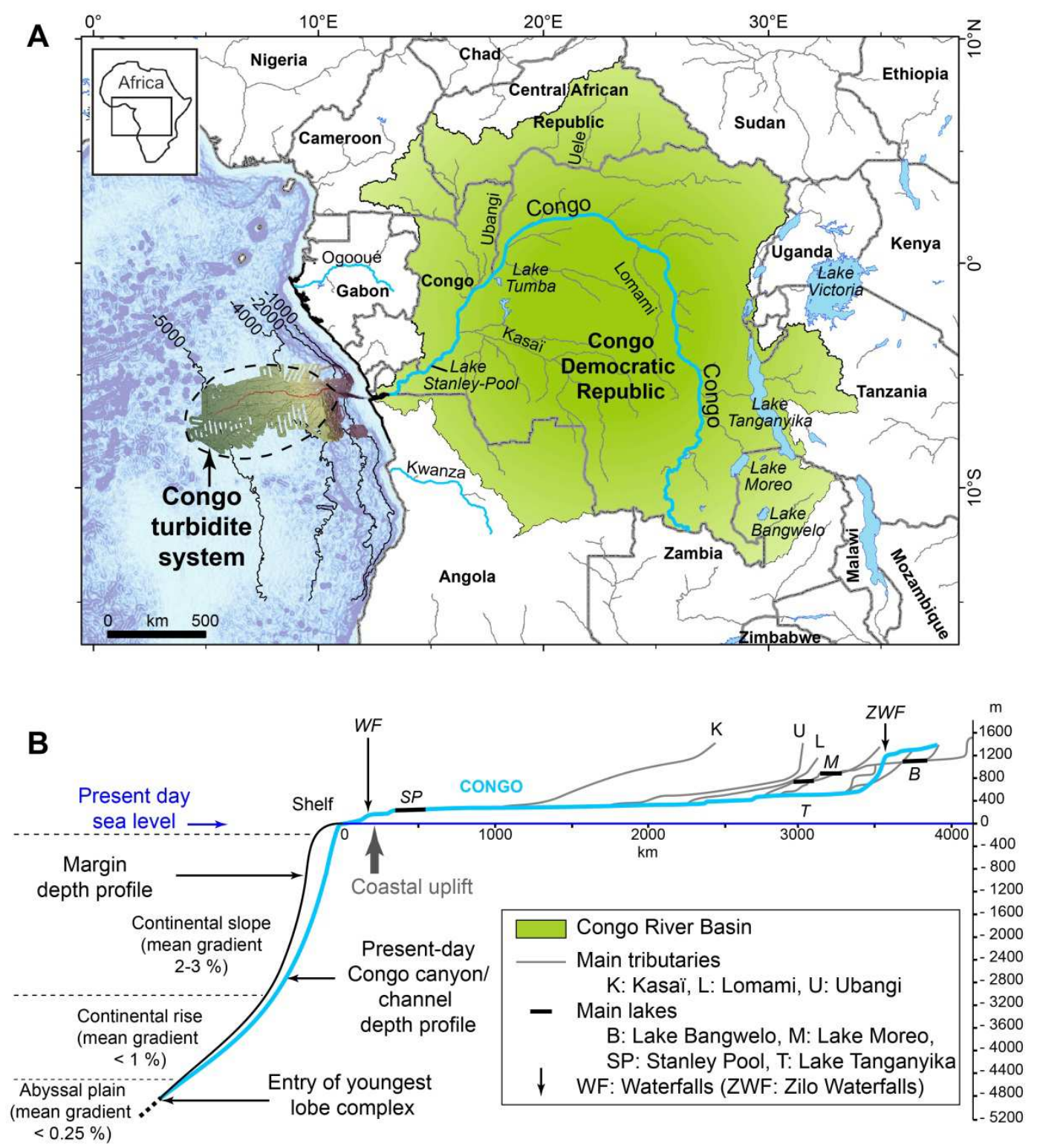

Fig. 1: (A) The Congo sedimentary system from source (Congo River and its catchment) to sink (Quaternary turbidite system). (B) Channel depth profile of the Congo River (light blue) and its tributaries (from Devroey, 1941 and Moguedet, 1988) and of the Congo canyon and channel (modified from Babonneau et al., 2005). Vertical exaggeration x 370 . 
The Congo Turbidite System is currently an active system (Droz et al., 2003, 1996; Heezen et al., 1964;

Khripounoff et al., 2003; Rigaut, 1997; Van Weering and Van Iperen, 1984) due to its physical connection with the Congo River at all sea-level positions. It is also characterized by an abundance of channel-levee systems visible on the seafloor (Droz et al., 2003; Marsset et al., 2009; Savoye et al., 2000) that could be related to favorable conditions which prevented the burying or reworking of these systems, such as: (1) the absence of physiographical confinement resulting in a widespread deposition, the small amount of overlap of individual fans, and minimal burying of channels and (2) the absence of large mass-transport deposits able to obliterate the channel network.

Droz et al. (2003) and Marsset et al. (2009) showed that the architecture of the Quaternary Congo fan results from the stacking of channel-levee systems grouped into three fans, the Northern Fan (780-540 ka), the Southern Fan (540-210 ka), and the Axial Fan (210 ka to present), in response to successive major upfan channel avulsions (Fig. 2).
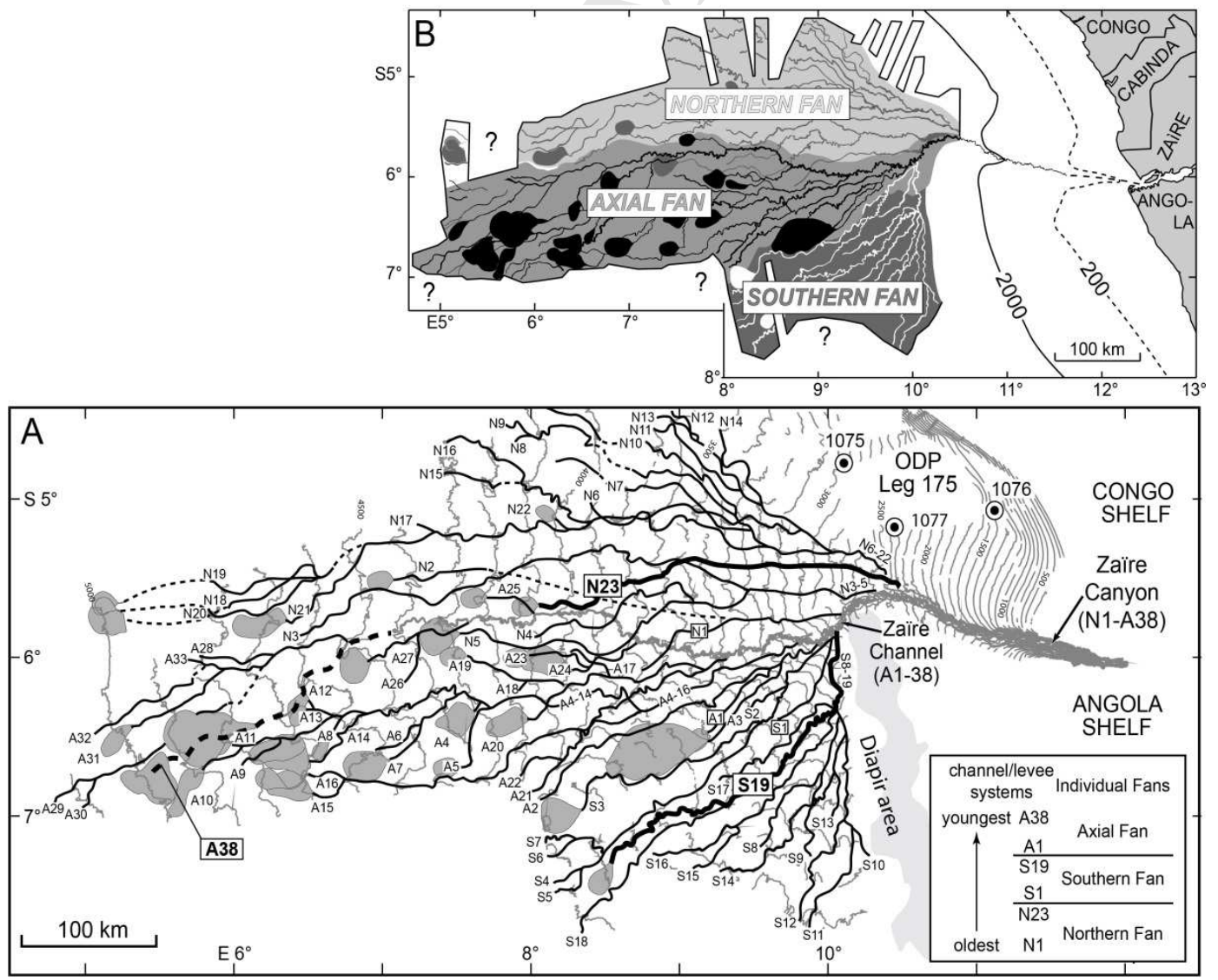
Fig. 2: Distribution of the channel-lobe systems in the Quaternary Congo turbidite system (modified from Marsset et al., 2009). (A) Channel-lobe map. Grey lobe-shaped features are terminal lobes. (B) The three individual fans.

As observed in many fans (e.g. Bouma et al., 1985; Damuth and Flood, 1983; Kolla and Coumes, 1987) only one channel-levee of the Congo Fan is active at any given time (Droz et al., 1996; Rigaut, 1997; Savoye et al., 2000) and the abandonment of the active channel is accomplished through avulsion of the feeder channel which can be a gradual but generally non-reversible process (Droz et al., 2003).

The third important characteristic of the Congo Fan is the frequent occurrence of channel entrenchment observed both on buried channels (Turakiewicz, 2004) and on the active channel (Babonneau et al., 2004, 2002). Channel entrenchment enhances the confinement of turbidity currents and allows them to maintain their energy far downstream in the channel and increases their erosional capacity (Babonneau et al., 2004). The channel map of Marsset et al. (2009) (Fig. 2) indicates that downstream of most channel-levees are lobeshaped seismic units, called terminal lobes by these authors. Marsset et al. (2009) use terminal lobes as a general term for channel-mouth lobes, whatever their location, up or downfan. These terminal lobes form high aspect ratio, convex-up deposits on the seafloor, and are fed by a network of superficial channels (called lobe channels by Marsset et al., 2009) extending from the mouth of the channel-levee systems. In addition, based on very high-resolution $3.5 \mathrm{kHz}$ data, Bonnel (2005) suggests that a terminal lobe can be a stack of even smaller lobes. At the termination of the active channel is a cluster of five $20-25 \mathrm{~m}$ thick lobes, called the lobe complex by Marsset et al. (2009), located on the northern side of the propagating channel termination (Babonneau, 2002; Babonneau et al., 2002) This lobe complex could have been deposited during the Holocene (Dennielou et al., 2003). Core analysis (Babonneau, 2002) revealed that levees of the youngest channel of the Axial Fan, as well as the body of the lobes, consist mainly of clay and silt and that coarse sediments (sand) are restricted to channel-fills including the small distributive channels on the lobes. 


\section{Material and methods}

Between 1992 and 2011 the French scientific community, led by IFREMER in partnership with Total, conducted a large investigation of the Congo Turbidite System with 9 geological and geophysical sea-cruises including GUINESS I (Cochonat and Robin, 1992), ZAÏANGO I and II (Cochonat, 1998; Savoye, 1998) and REPREZAÏ I and II (Droz and Marsset, 2011; Marsset and Droz, 2010). The results presented in this paper are based on the analysis of the geophysical data sets acquired during these cruises, including multibeam bathymetry and imagery, sub-bottom profiles, and single and multichannel seismic profiles (Table 1).

\begin{tabular}{|c|c|c|c|c|c|c|c|c|c|}
\hline \multirow[b]{2}{*}{ Cruises } & \multirow[b]{2}{*}{$\begin{array}{l}\text { Speed } \\
\text { (kts) }\end{array}$} & \multicolumn{3}{|c|}{ Seismic configuration } & \multicolumn{2}{|c|}{ Sub-Bottom Profiler } & \multicolumn{3}{|c|}{ Multibeam Echo Sounder } \\
\hline & & Source & Streamer & $\begin{array}{l}\text { Vertical } \\
\text { resolution } \\
(\mathrm{m})\end{array}$ & $\begin{array}{l}\text { Frequency } \\
\qquad(\mathrm{kHz})\end{array}$ & $\begin{array}{l}\text { Vertical } \\
\text { resolution } \\
(\mathrm{m})\end{array}$ & MES & $\begin{array}{l}\text { Horizontal } \\
\text { resolution } \\
(\mathrm{m})\end{array}$ & $\begin{array}{l}\text { Vertical ' } \\
\text { resolution } \\
(\mathrm{m})\end{array}$ \\
\hline $\begin{array}{c}\text { GUINESS } 1 \\
1992\end{array}$ & 10 & $\begin{array}{l}2 \mathrm{Gl} \\
\text { guns }\end{array}$ & $\begin{array}{l}\text { Single } \\
\text { channel }\end{array}$ & 30 & 3,5 & 0.30 & $\begin{array}{c}\text { Simrad } \\
\text { EM12 } \\
13 \mathrm{kHz}\end{array}$ & & \\
\hline $\begin{array}{c}\text { ZAIIANGO } \\
1 \text { and } 2 \\
1998\end{array}$ & $9-10$ & $\begin{array}{l}2 \mathrm{Gl} \\
\text { guns }\end{array}$ & $\begin{array}{c}6 \\
\text { channels }\end{array}$ & $15-20$ & 3,5 & 0.30 & $\begin{array}{l}\text { Simrad } \\
\text { EM12 } \\
13 \mathrm{kHz}\end{array}$ & 100 & $\begin{array}{l}0.5 \% \\
\text { water } \\
\text { depth }\end{array}$ \\
\hline $\begin{array}{c}\text { ZAÏANGO } 2 \\
1998\end{array}$ & 5 & $\begin{array}{c}4 \mathrm{Gl}+2 \\
\text { mini-Gl } \\
\text { guns }\end{array}$ & $\begin{array}{c}96 \\
\text { channels }\end{array}$ & 10 & 3.5 & 0.30 & $\begin{array}{l}\text { Simrad } \\
\text { EM12 } \\
13 \mathrm{kHz}\end{array}$ & & \\
\hline $\begin{array}{c}\text { REPREZAÏ } \\
1 \\
2011\end{array}$ & $8-9$ & $\begin{array}{l}2 \text { mini- } \\
\text { Gl guns } \\
(45 \text { and } \\
105 \mathrm{ci})\end{array}$ & $\begin{array}{c}24 \\
\text { channels }\end{array}$ & & $1.8-5.3$ & 0.30 & $\begin{array}{c}\text { SeaBat } \\
7150 \\
12 \mathrm{kHz}\end{array}$ & 50 & $\begin{array}{l}0.5 \% \\
\text { water } \\
\text { depth }\end{array}$ \\
\hline $\begin{array}{c}\text { REPREZAÏ } \\
2 \\
2011\end{array}$ & $4-5$ & $\begin{array}{l}6 \text { mini- } \\
\text { Gl guns } \\
(24 \text { and } \\
15 \mathrm{ci})\end{array}$ & $\begin{array}{c}96 \\
\text { channels }\end{array}$ & 3 & $1.8-5.3$ & 0.30 & $\mathrm{~N} / \mathrm{A}$ & $\mathrm{N} / \mathrm{A}$ & $\mathrm{N} / \mathrm{A}$ \\
\hline
\end{tabular}

Table 1: Summary of used geophysical data and theoretical resolutions. MES: Multibeam Echo-Sounder.

\subsection{Bathymetric data}

The general bathymetric map has been compiled from multibeam echo sounder data acquired during several cruises (Table 1). Data have been processed with Caraïbes software (developed by Ifremer). The processing of EM12 data provided a Digital Terrain Model (DTM) with $100 \mathrm{~m}$ grid spacing. A $50 \mathrm{~m}$ grid spaced DTM was obtained in areas where SeaBat 7150 data were acquired. In both cases, the vertical resolution does not exceed $0.5 \%$ of the water depth (Table 1$)$. 
Small morphological details in deep water environments are often difficult to image, especially when slope gradients are low. In order to enhance the bathymetric details and reveal small-scale structures, we processed the DTM using the Sonarscope software developed by Ifremer (http://flotte.ifremer.fr/flotte/Presentation-de-laflotte/R-D-projets/SonarScope), by calculating a polynomial surface corresponding to the mean slope of the area and representative of the topographic trend. This polynomial surface was subtracted from the initial DTM (Fig. 3A). In order to avoid the effects of the high topographic plateau and diapir areas, a mask had to be applied on the upstream part of the DTM.

The resulting map (Fig. 3B right, see also Fig. 6) is called "relief map" and better shows the channel-levee and lobes that are identified as positive relief (values $>0$, yellow to red). This map also enhances negative relief (values $<0$, dark blue to light green), where some channels can also be observed. This type of topographic representation must be interpreted carefully, especially at the limits of the grid, where a decrease in the local slope can result in an apparent thickening (Fig. 3B right).

\begin{tabular}{|c|c|c|c|c|c|}
\hline & slope + relief & & slope & & relief enhanced \\
\hline 总 & 部 & - & 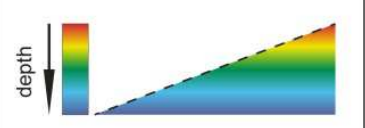 & $=$ & $\begin{array}{l}\max _{\min }=\infty \\
\mathrm{m}\end{array}$ \\
\hline 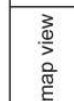 & 11 & & & & \\
\hline
\end{tabular}
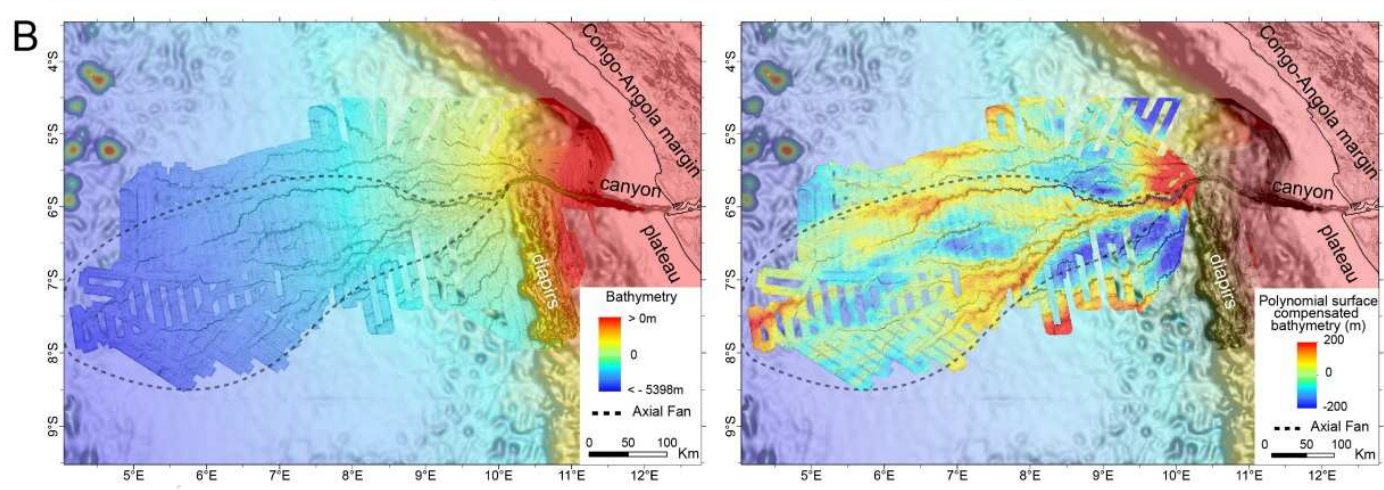

Fig. 3: (A) Principle of the polynomial surface-compensated bathymetry, showing the enhancement of the relief obtained with processing the original DTM by subtracting the polynomial surface calculated by Sonarscope software (developed by Ifremer). (B) Application to the Congo turbidite system. Left: Original DTM which clearly shows the channel network, but fails to image faint morphological variations. Right: Relief map: 
bathymetric map corrected from the general slope, which better illustrates the relief variations in the basin. Note the apparent "thickening" at the western and southeastern part of the map, at the limit of the grid, probably linked to a decrease in slope. Base map: ETOPO1 bathymetry (Amante and Eakins, 2008).

\subsection{Seismic data}

The results presented here are based on part of the large Congo seismic data set obtained on the turbidite system, representing about $16,000 \mathrm{~km}$ of the total length of $27,000 \mathrm{~km}$ of available seismic lines and subbottom profiles (Table 1). In the Axial Fan area, seismic lines are mostly oriented NNW-SSE, and their spacing is variable with a minimum of $5 \mathrm{~km}$ and a maximum of $26 \mathrm{~km}$ (Fig. 4). Vertical resolution of used seismic data (Table 1) ranges from $30 \mathrm{~m}$ (single channel data) to $0.30 \mathrm{~m}$ (sub-bottom profiles), making the data set heterogeneous in term of the size of identifiable objects. In order to maintain a homogeneous quantitative analysis we chose to limit our analysis to sedimentary objects thicker than $15 \mathrm{~m}$, which is the resolution of the majority of our seismic data.

The ZAÏANGO seismic data set was processed using PROMAX software (Droz et al., 2003). The REPREZAÏ seismic data was processed onboard by using the in-house QC-SISPEED IFREMER software for multichannel seismic data (quality control, filtering, migration constant speed $1500 \mathrm{~m} / \mathrm{s}$ ), and QC-SUBOP software for SBP data (quality control, gain, envelop). These data sets have been analyzed using the Kingdom Suite (IHS Global Inc.) seismic interpretation software.

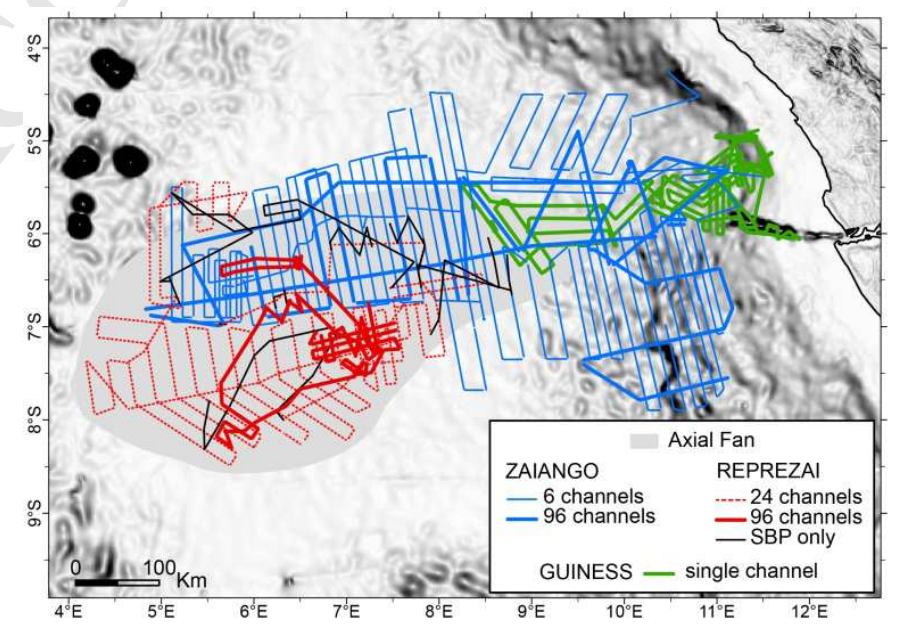


Fig. 4: Location of seismic data acquired during GUINESS, ZAIIANGO, and REPREZAÏ surveys, and location of the Axial Fan (grey area). Base map: slope map of the ETOPO1 bathymetry (Amante and Eakins, 2008).

\subsection{Channel-lobes map}

We combined these different types of data in order to provide an up-to-date version of the channel map previously established by Marsset et al. (2009). Channels and lobes were identified by their seismic facies as described in Droz et al. (2003). Channel-levee systems are lens-shaped seismic bodies formed by the association of (i) the channel facies characterized by a "v" or" u" shape, sometimes filled by discontinuous, unconformable high-amplitude reflectors (HAR) and (ii) the levees facies most commonly characterized by lower amplitude, higher frequency, and good continuity of the seismic reflectors. Terminal lobes are also lensshaped units but are made of either transparent facies or discontinuous and contorted high-amplitude reflectors.

The $2 \mathrm{D}$ extension of the channels was defined by the analysis of the bathymetric map, the relief map (see 1.1 Fig. 3), the backscatter image, and the slope map of the fan. The relative chronostratigraphy of the channels and their associated terminal lobes was established by the observation on seismic profiles of the angular relationships (principle of superposition) of the channel-levee systems downstream from avulsion points (Fig. 5A). When possible, the chronology was determined close to the avulsion points.

The chronology of the channel-levee systems was determined with the assumption that, because an avulsion results in the abandonment of the ancient channel down-dip the avulsion point, only one channel is active at any time (Curray and Moore, 1971; Damuth and Flood, 1983; Droz et al., 2003; Flood et al., 1991). The avulsion generates a disruption of the equilibrium profile and the abandoned portion of the initial channel can no longer serve as a conduit for turbidity currents (Flood et al., 1991; Lopez, 2001; Pirmez et al., 1997). The isochron and isopach maps provided in the paper (see Fig. 8) and the calculation of the Axial Fan total volume have been realized with Kingdom Suite software. 


\subsection{Measurement of architectural parameters and diagram construction}

Based on the new channel map, we used the same method as reported in Marsset et al. (2009), which consists of measurements, from a common reference point in the canyon, of (1) the length along the channel to the entry of the terminal lobe (CL: Channel Length), (2) the distance along the channel to the avulsion point from which the channel is issued (DA: distance to avulsion point), (3) the length of the new channel portion (AL, or avulsion length, defined as the distance, along the axis, of a channel from the avulsion point to the inlet of its terminal lobe and obtained by subtracting $\mathrm{DA}$ from $\mathrm{CL}$ ), and (4) the number of avulsion points (NbA) from which a channel is issued, between the reference point and the entry of its terminal lobe (Fig. 5B). The reference point was arbitrarily located on the canyon course upstream from the most proximal avulsion point, at $230 \mathrm{~km}$ (distance along the channel) from the canyon head. CL and DA were measured using ArcGis software.

These parameters are reported on the diagram in their relative chronological order (Fig. 5C). Where a lobe is absent (either because no lobe developed at the termination of the channel, or the seismic grid was inadequate to reveal the lobe), the measured length corresponds to the distance between the reference point and the known end of the channels and is shown by dashed lines on the $C L$ and $A L$ diagrams (Fig.5C). Note that, in order to be consistent with low-resolution seismic data, the channel-levee-lobe systems thinner than $15 \mathrm{~m}$ and visible on high-resolution seismic data, though drawn on the channel-lobe map, were not taken into consideration in the diagrams. 

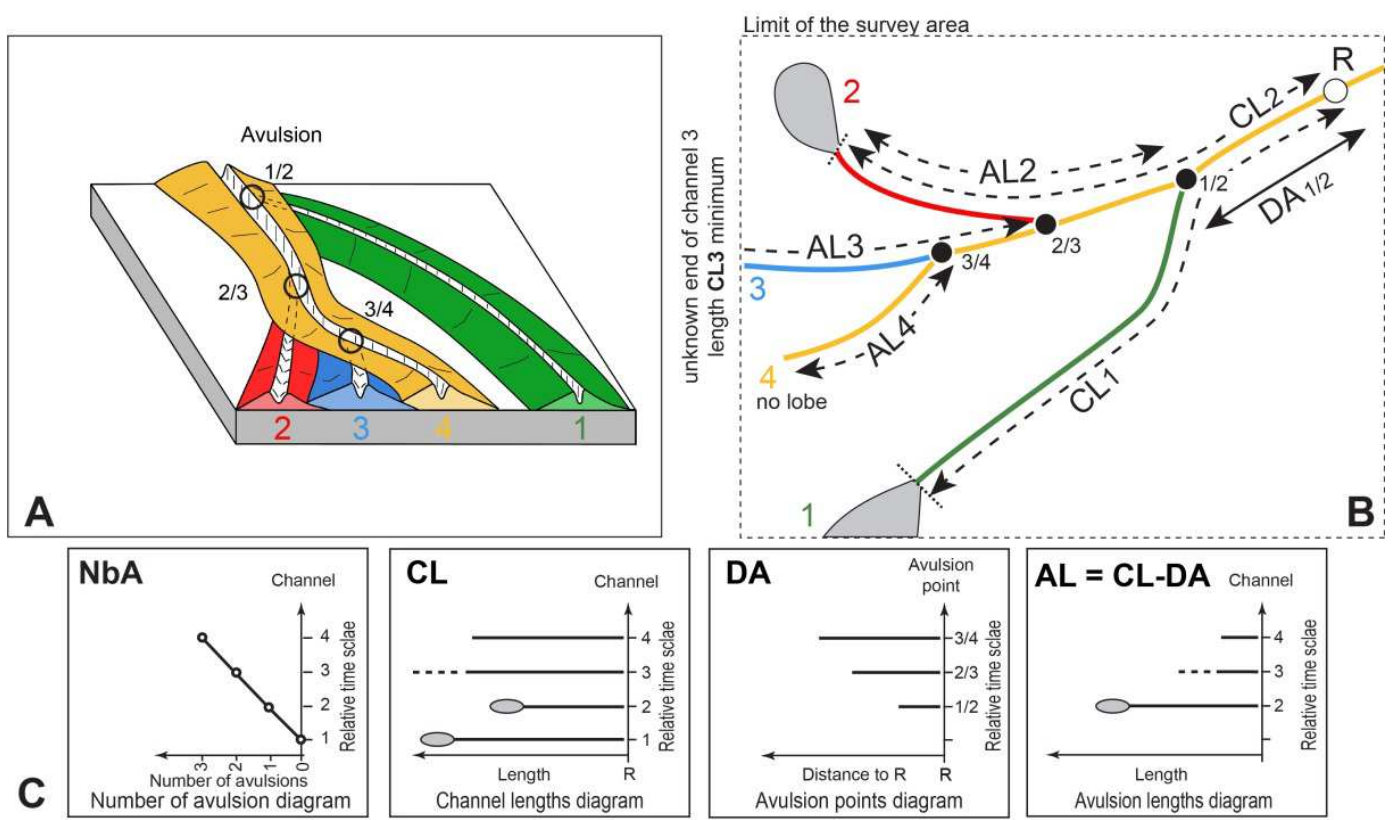

Fig. 5: Principles of measurements of the architectural parameters with $\mathrm{CL}$ (Channel Length), DA (Distance of Avulsion), $\mathrm{AL}$ (Avulsion Length), where $\mathrm{CL}=\mathrm{DA}+\mathrm{AL}$. (A) Principle of superposition that was used to establish the relative chronology of channels (channels 1 to 4 in order of decreasing age). (B) Schematic channel network illustrating the measured distances. DA1/2, distance of the avulsion point 1/2 (from channel 1 to channel 2) to the reference point $R ; C L 1$, along-channel distance from the inlet of the lobe to the reference point $R$ (total length of channel 1). (C) Construction of the diagrams. Note that the vertical scale is a relative time scale. Number of avulsions diagram $(\mathrm{NbA})$ : for each channel, the total number of avulsions along its course. Avulsion points diagrams (DA): the avulsion point $1 / 2$ is attributed to channel 2. Channel-lengths diagram $(\mathrm{CL})$ : the grey lobe-shaped features are terminal lobes, indicating that the plotted distance is the true length of the channel; dashed lines indicate that the channel could be longer. Avulsion length diagram (AL): length of the newly created channel following the avulsion, from the avulsion point (DA) to the inlet of the lobe. Note that for the first channel, AL cannot be defined as there is no avulsion point. Modified from Marsset et al. (2009). 


\subsection{Lobe area and volume calculations}

In order to compare the evolution of lobe volumes and architectural parameters, we measured the maximal length (L), width (W), and thickness $(T)$ of the lobes delineated from our seismic interpretation. $L$ and $W$ were measured and then lobe areas were calculated on the channel-lobe map using ArcGis software. Thicknesses were measured on seismic lines in two-way travel time and converted into meters using a velocity of $1480 \mathrm{~m} / \mathrm{s}$ for depths $<35 \mathrm{mbsf}$ and $1550 \mathrm{~m} / \mathrm{s}$ for greater depths, as measured at site 1077 of ODP Leg 175 (Wefer et al., 1998b).

Following the volume calculation method used by Prélat et al. (2009), lobe volumes (V) have been estimated assuming an ellipsoidal shape:

$V=4 / 3 \pi * 1 / 2 L * 1 / 2 W * 1 / 2 T$,

where $L$ is the maximum length, $W$ is the maximum width, and $T$ is the maximum thickness of a lobe, except for one lobe ( $\mathrm{A} \times 50$, see supplementary material A) for which the surficial area was so great that we choose to consider a mean thickness.

This approximation considers the lobes as symmetrical objects, both vertically and laterally (ellipsoid). However, the Axial Fan lobes are clearly not ellipsoidal (see section 4.2.4.1). They are mostly slightly elongated and fan shaped in plan view (the apex of lobes being shorter than the middle part) (see section 4.2.4.1), and mainly lenticular in cross-sections, either along or perpendicularly to the flow direction. The calculated volumes are therefore probably overestimated. However, we adopted this method of volume estimation to be able to compare our results with those of Prélat et al. (2010) (see section 4.3.1).

\section{Results}

\subsection{Morphological characteristics of the Axial Fan}

The bathymetric map and sections of the Axial Fan (Fig. 6) highlight two main depositional axes: an E-W group of northern channels, including the presently active channel, and a NE-SW group of southern channels, which is comprised of channels that evolve downstream from highly sinuous to relatively straight at their terminations. They are separated by a topographic low including a few channels (central channels) that evolve 
downstream to a well-developed channel-levee system, the end of which remains unknown, indicating that the total length of the Congo Fan is greater than the explored $800 \mathrm{~km}$. The main depositional axes merge upstream, near the base of slope. The southern group of channels is laterally well-developed and fan-shaped while the northern one is narrower and composed of fewer channels (Fig. 6A).

The bathymetric section at the apex of the Axial Fan (section 1 in Fig. 6B) indicates that the present-day seafloor is sloping southeastward, the Southern Fan being $200 \mathrm{~m}$ deeper than the Northern Fan. The Axial Fan was emplaced between these older fans, but it seems that the Axial Fan did not totally fill the available empty space, leaving a deep low at the Southern Fan boundary and suggesting a state of disequilibrium. Downfan (cross-sections 2 to 4 in Fig. 6B), the Axial Fan progressively extends laterally along the two main depositional axes, but the central topographic low remains clearly visible on cross-sections 3 and 4 . 

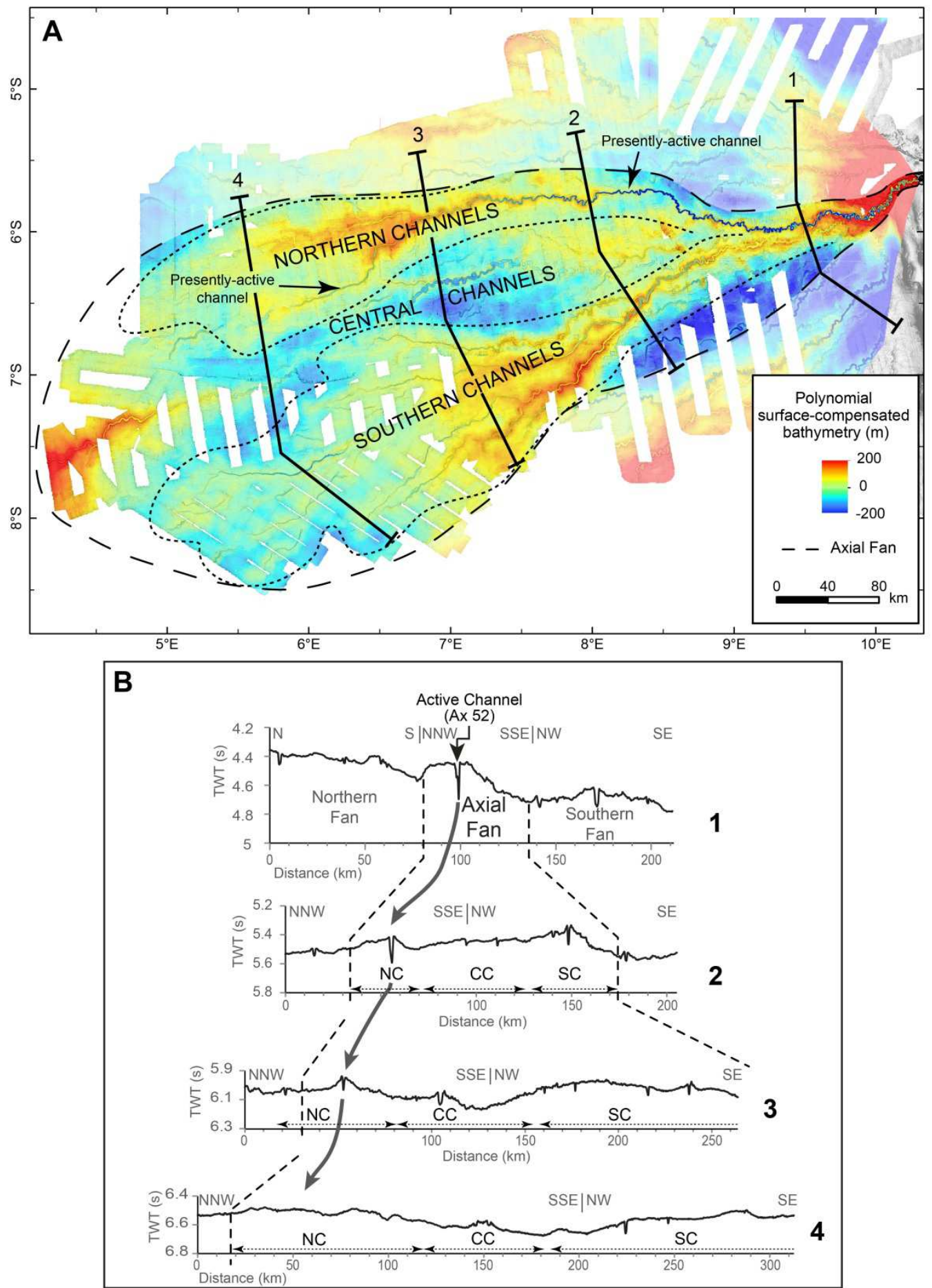

Fig. 6: Topography of the Axial Congo Fan. (A) Relief map (see 3.1 about the processing of bathymetric data). Dashed line: approximate boundaries of the Axial Fan. Dotted lines: boundaries of the main depositional axes (Northern and Southern channels) highlighted by yellow to light green colors. These depositional axes are separated by a topographic low (dark blue to light blue) where channels are observable (Central channels) (B) 
Serial bathymetric cross-sections from the apex to the distal parts of the Axial fan (sections are in s twt to be easily compared with those presented in Fig. 9). NC: northern channels; CC: central channels; SC: southern channels. Vertical Exaggeration: x50.

\subsection{Architecture of the Axial Fan}

\subsubsection{Revisited channel-lobes map}

The re-interpretation of previous GUINESS and ZAIIANGO seismic data in the light of new REPREZAÏ data resulted in a complete and accurate channel-lobe map of the Axial Fan (Fig. 7). Main differences with the map produced by Marsset et al. (2009) consist of (1) the addition of 31 previously unidentified channels, and the introduction of "Undifferentiated unit Packages" (UP) representing very thick units of probably stacked-up lobes with no identified feeder channels (see 4.2 .5 below); (2) the revision of some channel courses (A05 and A17 and upfan portions of some channels); (3) the revision of the relative age of 2 channels (A03 and A04); (4) the removal of 7 channels re-interpreted as not belonging to the Axial Fan, but rather to the Northern Fan (A08, A26, A29, A30, A31). In addition, we made a few modifications to lobe shapes and size (e.g. A03, A11). The very small channels that feed lobes (herein called lobe channels) and are under the seismic resolution (i.e. thinner than $15 \mathrm{~m}$ ) are indicated in brown on the map (Fig. 7). Uncertainties remain for the connection of some channels, especially when they are partially buried. In that case, these channels are represented by dashed lines.

The above-mentioned changes led us to list a total of 52 channels constituting the Axial Fan plus a few small, unlabeled channels. They also led us to modify the chronology of channel formation and to re-label the channels. For easier reading and understanding, we provide a table (Table 2) of new (this work) and previous numbering (Marsset et al., 2009). We will refer exclusively to the new numbering. 


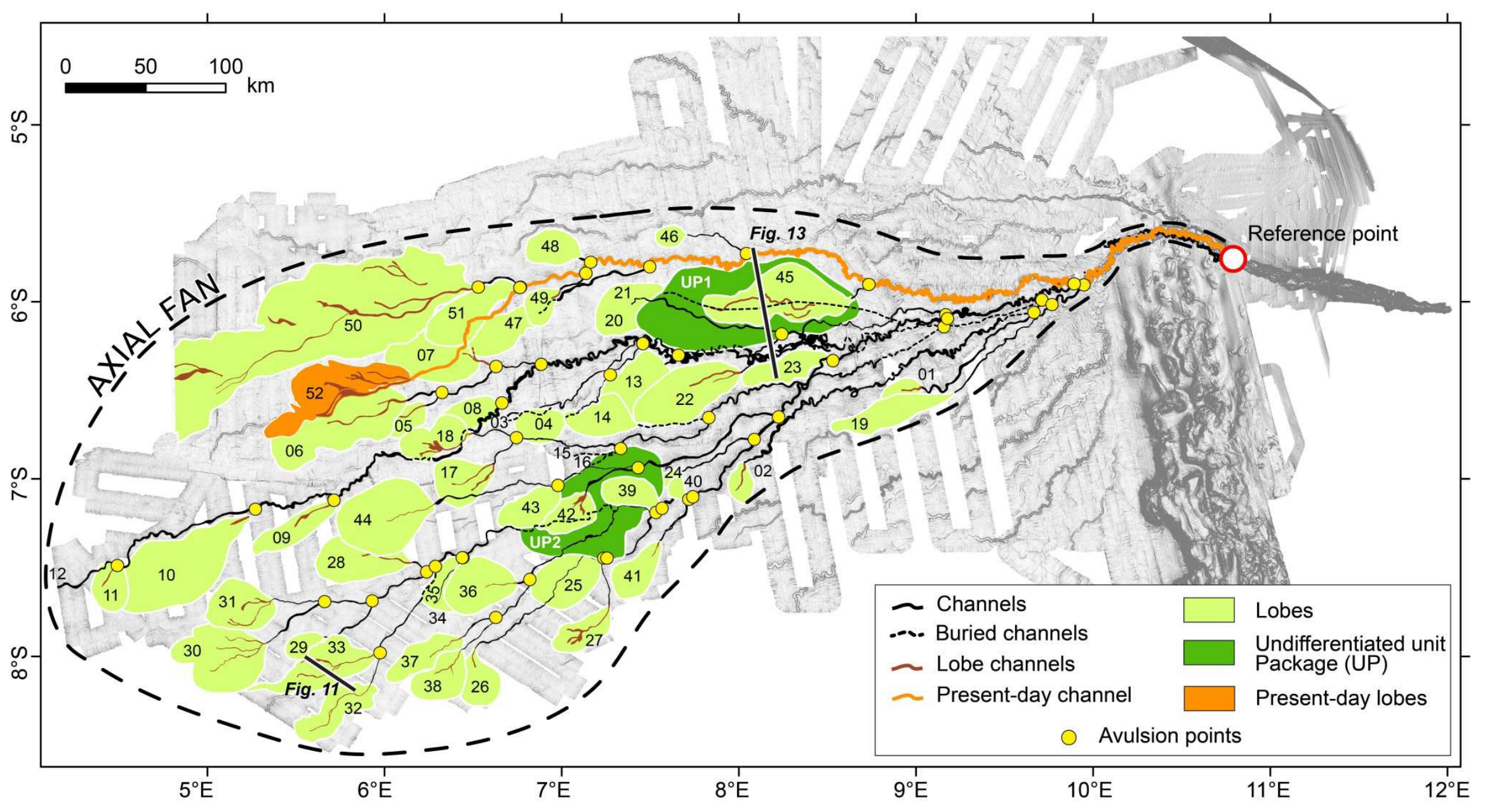


Fig. 7: New channel-lobes map of the Late Quaternary Axial Congo Fan established from bathymetric and seismic data (multichannel seismic and Sub-Bottom Profiler data). Chronologically referenced channels, terminal lobes, avulsions points and UPs are drawn on the slope map of the whole fan. Present-day channel and lobes (simplified from Babonneau, 2002 and Bonnel, 2005) are in orange. Note the reference point used for measurements. The location of the seismic sections of Fig. 11 and 13 are indicated as black straight lines

\begin{tabular}{|c|c|c|c|c|c|c|c|}
\hline $\begin{array}{l}\text { New } \\
\text { labels } \\
\text { (this } \\
\text { study) }\end{array}$ & $\begin{array}{l}\text { Previous } \\
\text { labels } \\
\text { (Marsset } \\
\text { et al., } \\
\text { 2009) }\end{array}$ & $\begin{array}{l}\text { New } \\
\text { labels } \\
\text { (this } \\
\text { study) }\end{array}$ & $\begin{array}{l}\text { Previous } \\
\text { labels } \\
\text { (Marsset } \\
\text { et al., } \\
\text { 2009) }\end{array}$ & $\begin{array}{l}\text { New } \\
\text { labels } \\
\text { (this } \\
\text { study) }\end{array}$ & $\begin{array}{c}\text { Previous } \\
\text { labels } \\
\text { (Marsset } \\
\text { et al., } \\
2009 \text { ) }\end{array}$ & $\begin{array}{l}\text { New } \\
\text { labels } \\
\text { (this } \\
\text { study) }\end{array}$ & $\begin{array}{c}\text { Previous } \\
\text { labels } \\
\text { (Marsset et al., } \\
\text { 2009) }\end{array}$ \\
\hline $\mathrm{Ax01}$ & $\mathrm{A} 01$ & $A \times 15$ & - & $A \times 28$ & - & $\mathrm{Ax41}$ & - \\
\hline $\mathrm{Ax} 02$ & $\mathrm{~A} 02$ & Ax16 & - & $A \times 29$ & - & $A \times 42$ & - \\
\hline $\mathrm{Ax03}$ & A06 & $A \times 17$ & A15 & $A \times 30$ & - & $A \times 43$ & - \\
\hline $\mathrm{Ax04}$ & A07 & Ax18 & A16 & $A \times 31$ & - & Ax44 & A22 \\
\hline Ax05 & A09 & Ax19 & $\mathrm{A} 03$ & $\mathrm{~A} \times 32$ & & Ax45 & $\mathrm{A} 17, \mathrm{~A} 23, \mathrm{~A} 24$ \\
\hline $\mathrm{Ax} 06$ & A11 & Ax20 & - & $A \times 33$ & & $A \times 46$ & A25 \\
\hline $\mathrm{A} \times 07$ & $\mathrm{~A} 12, \mathrm{~A} 13$ & UP1 & - & $A \times 34$ & - & $A \times 47$ & A27 \\
\hline $\mathrm{Ax08}$ & A14 & $A \times 21$ & A19 & $A \times 35$ & - & $A \times 48$ & - \\
\hline Ax09 & - & $A \times 22$ & A20 & UP2 & - & $A \times 49$ & - \\
\hline$A \times 10$ & - & A $\times 23$ & - & $A \times 36$ & - & $A \times 50$ & A28, A32, A33 \\
\hline$A \times 11$ & - & $A \times 24$ & A21 & $\mathrm{A} \times 37$ & - & $A \times 51$ & - \\
\hline$A \times 12$ & - & $A \times 25$ & - & $A \times 38$ & - & Ax52 & A38 \\
\hline$A \times 13$ & A04 & A $\times 26$ & - & Ax39 & - & & \\
\hline Ax14 & A05 & A $\times 27$ & - & $\mathrm{A} \times 40$ & - & & \\
\hline
\end{tabular}

Table 2: Equivalence table of channel labels between this study and that of Marsset et al. (2009).

\subsubsection{Fan scale deposition}

The isochron map of the Axial Fan basal surface represents the paleotopography at the time of fan initiation (Fig. 8A-B). This map highlights a central hummocky, triangular, topographic low sloping SW between two longitudinal highs corresponding to the tops of the Southern and Northern Fans. Inside this central low, three main axes (NA, CA, SA, Fig. 8A) are observed that served as preferential depositional axes for the Axial Fan. The nature of the Axial Fan substrate is unknown because of the limited penetration of seismic data. However, older channel-levee systems are observed locally, suggesting either channels belonging to the Northern and/or Southern Fans or an even older fan.

Post-depositional loading related to the Axial Fan thickness has not been taken into consideration while establishing the isochron map of the basal surface (Fig. 8A-B). However the usual first order approximation 
considers that the loading effect represents about $1 / 3$ of the thickness of the deposits (Allen and Allen, 2013). So in our case ( $70 \mathrm{~m}$ as the mean thickness of the Axial Fan, Fig. $8 \mathrm{C}$ ), the initial basal topography of the fan was possibly only $\sim 25 \mathrm{~m}$ shallower, therefore indicating that the topographic low imaged in Fig. $8 \mathrm{~A}$ and B was indeed present between the Northern and Southern Fans.

The mean thickness of the Axial Fan is $\sim 90 \mathrm{~ms}$ twt (i.e. $\sim 70 \mathrm{~m}$ ) (Fig. 8C), maximum thicknesses (up to $0.37 \mathrm{~s}$ twt, i.e. $290 \mathrm{~m}$ ) being located along the southern boundary of the fan. These maximum thicknesses correlate with the southern channels identified by the morphological analysis (SC in Fig. 6B) and match with the southern axis observed on the isochron map of the fan basement (Fig. 8A-B). To the North, the Axial Fan is characterized by much lower thicknesses, possibly due to a more elevated initial seafloor (Northern Fan deposits).

The total volume of the Axial Fan is approximately $8500 \mathrm{~km}^{3}$. This value is a minimum because the distal western parts of the Axial Fan are beyond the surveyed area.

Serial, upfan to downfan, cross-sections illustrate the widening and thinning of the Axial Fan (Fig. 9). Section 1 also shows the strong topographic contrast that prevailed before the deposition of the Axial Fan, the top surface of the Southern Fan being about $250 \mathrm{~ms}$ twt ( $>180 \mathrm{~m}$ ) lower than the top surface of the Northern Fan. This depth contrast progressively decreases towards the distal parts of the fan. 

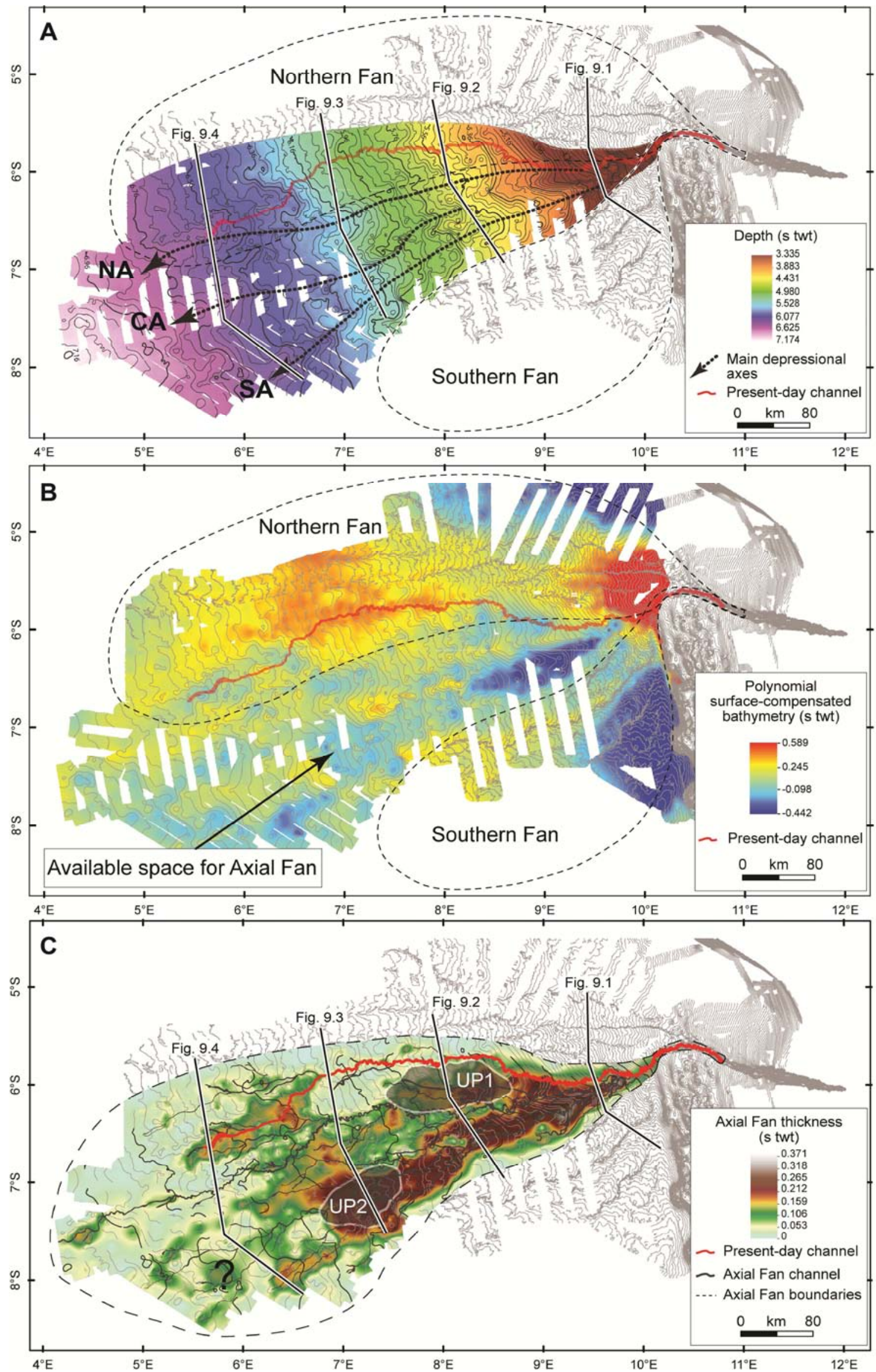
Fig. 8: Paleotopography of the Axial Fan basement and thickness map of the Fan. (A) Isochron map (in s twt) of the basement showing low topographic axes: NA (northern axis), CA (central axis), SA (southern axis). (B) Relief map (in s twt) of the Axial Fan basal surface. (C) Isopach map (in s twt): the lack of close reference to the basal surface of the Axial Fan in the most distal area leads to greater uncertainties. The black lines correspond to the cross-sections shown in Fig.9.

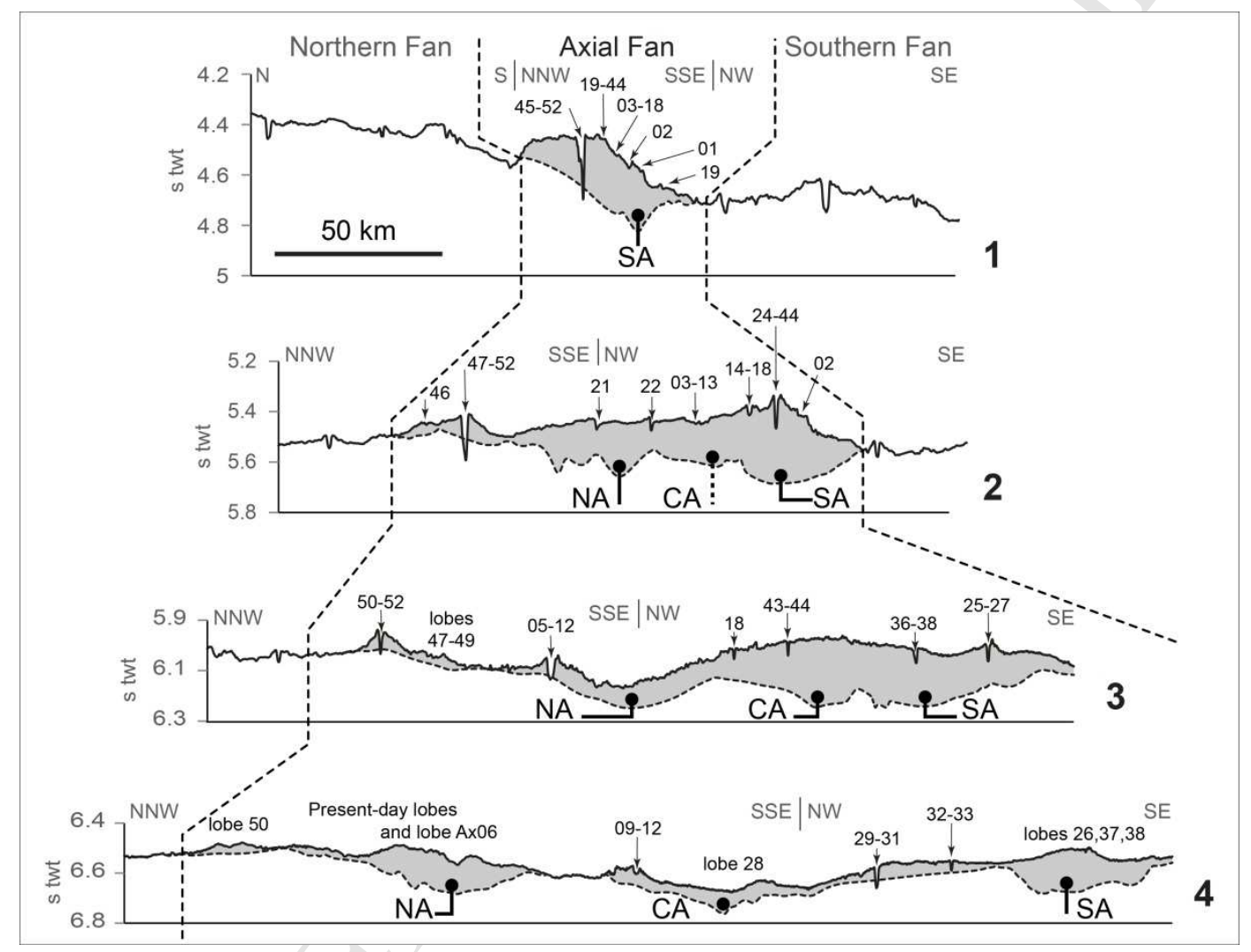

Fig. 9: Serial cross-sections from upfan (section 1) to downfan (section 4) of the Axial Fan. Same scale for each cross-section. Dashed lines: basal surface of the Axial Fan. NA (northern axis), CA (central axis) and SA (southern axis) point to the depositional axes visible at the base of the Fan. Vertical Exaggeration: $x 50$. Location of cross-sections in Fig. 8. 


\subsubsection{Growth pattern of channel-levee-lobe systems}

The seismic facies and morphology of channel-levee systems has been previously described in earlier works (Babonneau et al., 2005, 2004, 2002; Droz et al., 2003, 1996; Savoye et al., 2000). The new channel map provides more information on the growth pattern of channel-levee systems (Fig. 10).

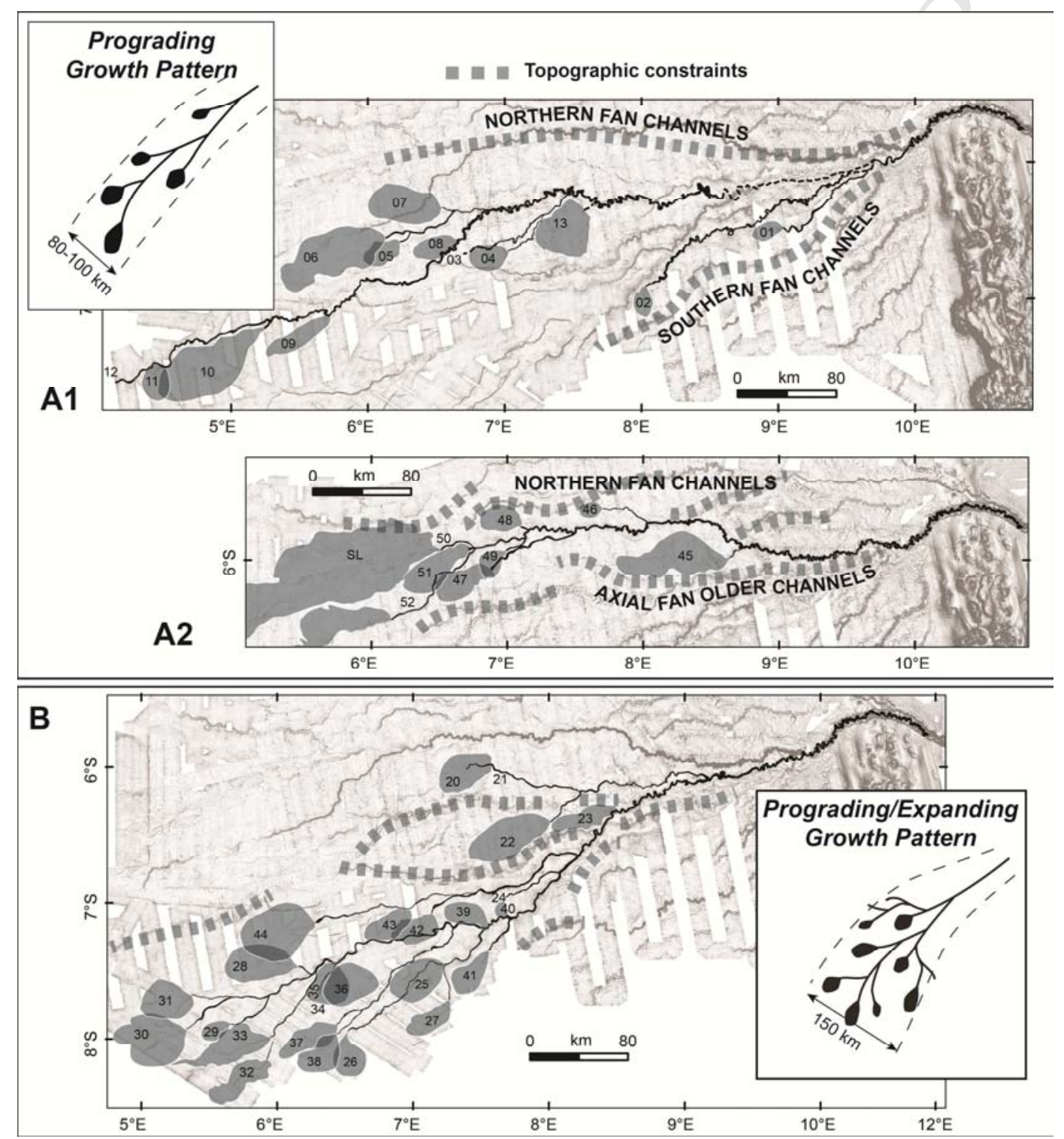

Fig. 10: Growth pattern of the Axial Congo Fan. (A) Example of mainly prograding poplar-tree-like network of channels (A1: channels Ax01-13; A2: channels Ax45-52). (B) Example of an oak-tree-like prograding and laterally expanding network of channels (channels Ax20-44). 
The triangular shape of the Axial Fan is the result of a combination of two main types of channel networks, which can be distinguished based on their basinward evolution. The first type of channel network (Ax01 to $A \times 13$ and $A \times 45$ to $A \times 52$ ) shows a prograding growth pattern (Figs. 10A1 and 10A2) resulting from successive basinward avulsions. This type of channel network shows a limited lateral extent $(80-100 \mathrm{~km})$ and a long downdip extent (more than $1000 \mathrm{~km}$, Fig. 10A1), evoking a poplar tree.

The second type of channel network (Fig. 10B) is characterized by a downfan lateral expansion developing a more complicated structure evoking an oak-tree. The lateral extent can reach $150 \mathrm{~km}$, i.e. almost twice the lateral extent of the prograding networks.

The prograding growth pattern occurs mainly upfan, where the Northern and Southern Fans, and the preceding Axial Fan depocenters, limit the available space laterally. The diverging prograding/expanding pattern develops downfan, where the depositional seafloor is mainly unconstrained.

\subsubsection{Terminal lobes}

Droz et al. (2003) provided a general description of the terminal lobes and Babonneau (2002) and Bonnel (2005) focused on the structure, composition, and dating of the lobes belonging to the presently active system (i.e. Ax52). In this paper, we provide a detailed and quantitative study of the seismic units observed at the termination of the channels, referring to their architecture, relationships to the channels, and evolution through space and time.

We use the term "lobe" or "terminal lobe" as a general term referring to lobe-shaped seismic units at the termination of channels.

\subsubsection{Seismic characteristics and stacking patterns}

Most of the channels pass into a seismic unit identified as a terminal lobe due to its typical lobe-shaped structure, which can form a slight bulge at the seafloor when not buried or deposited in topographic lows (Fig. 7 and Fig. 10). The lobes are often connected to small feeder channels called "lobe channels" that are generally under the air-gun's seismic resolution (i.e. about $15 \mathrm{~m}$, see 3.2) but are visible on sub-bottom profiles. When several lobe channels are recognized on a lobe-shaped unit, the limited resolution of seismic 
data does not enable us to discriminate between the contemporaneous or diachronous activity of these channels.

Most of these lobe-shaped units are characterized by a transparent or chaotic seismic facies, possibly with some high amplitude discontinuous reflections (Fig. 11A). The base of the units is unconformable and locally erosive. On very high-resolution data (SBP), the central part of the units generates an acoustic mask below (Fig. 11B), suggesting coarse material and/or rough micro-topography.

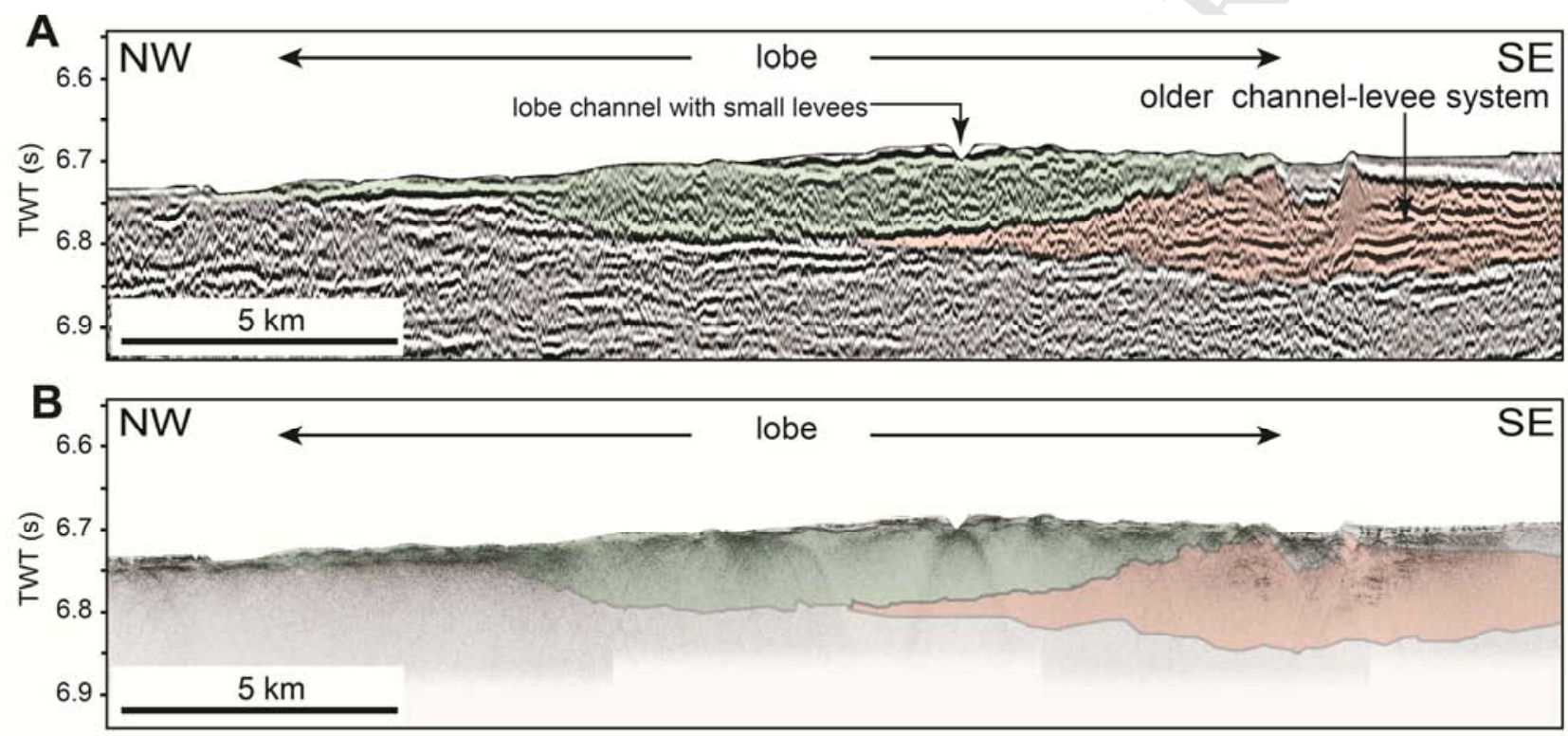

Fig. 11: Seismic facies of lobe Ax32. (A) 24 channels seismic cross-section. (B) Sub-bottom profiler (SPB) seismic cross-section. The lobe is topped by a small incised channel with thin lateral levees. On SBP data, the basal limits of the sedimentary units are not observable due to limited penetration, and come from the 24 channels seismic section. Vertical Exaggeration: x 19. Location of cross-sections in Fig. 7.

The distal fringes of the lobe-shaped units can be made of parallel reflectors. These bedded fringes have also been described at the youngest, active lobe (Ax52) (Babonneau, 2002; Bonnel, 2005).

In addition, some (<20\%) clusters of several seismic sub-units were recognized based on SBP observations (Fig. 12). Three types of clusters have been identified based on different stacking patterns. The radial clusters (Fig. 12A) correspond to a set of lobes clustered around a single avulsion node. A small lobe channel feeds 
each lobe of the cluster. After the deposition of the last lobe, the channel is abandoned. This type of cluster has been recognized at the termination of Ax22 and Ax30. Two types of progradational clusters are identified. In type I, the lobes are stacked laterally and the channel progrades while avoiding the preceding lobe sub-unit (Fig. 12B). This stacking pattern has been observed by Babonneau (2002) and Bonnel (2005) at the termination of the youngest channel of the Axial Fan (Ax52). We also identified it at the termination of channel Ax18. This type I progradational cluster corresponds to the "laterally offset lobes" observed by Morris et al. (2014) in the Karoo. A type II progradational cluster shows a channel prograding over the lobe without passing around, (Fig. 12C). Unfortunately, no dip seismic line is available to confirm this bathymetry-based assumption. This type of stacking pattern was observed at the termination of 4 channels (Ax25, Ax32, Ax33, Ax34-35). Type II corresponds to the "forward stepping frontal lobes" of Morris et al. (2014). 

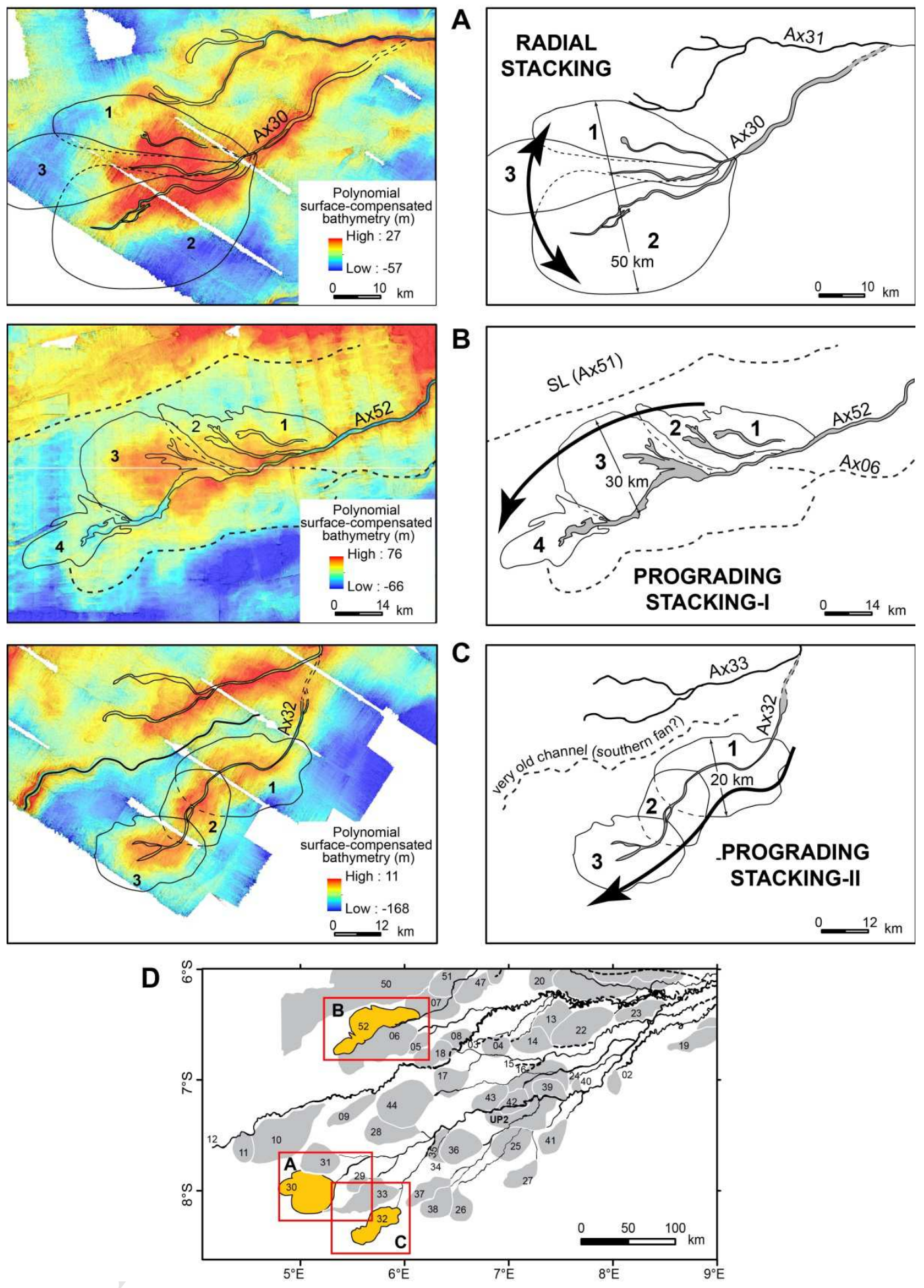

Fig. 12: Lobe clusters observed in the terminal lobes (lobes 1 to 3 or 4 , from the oldest to the youngest). Left: relief map; right: sketch of the lobes and their feeding channel. Black lines: youngest channels. Dashed lines: older channels, (A) Radial cluster of 3 lobes at the termination of channel Ax30, leading to the lateral spreading of the terminal lobe. (B) Progradational- cluster, type I, at the termination of the youngest channel of 
the Axial Fan (simplified from Babonneau, 2002): the channel keeps prograding by flowing around the preceding lobes. SL: Superficial lobe area (see section 4.2.3.2). (C) Progradational cluster, type II, at the termination of channel Ax32: the channel keeps prograding over its successive lobe sub-units. (D) Location of the maps $\mathrm{A}$ to $\mathrm{C}$.

\subsubsection{The superficial lobes area}

Channel Ax50, to the north of the youngest $A \times 52$ channel, feeds a wide area of vertically or laterally stacked sub-units fed by several secondary lobe channels. The thin sub-units are difficult to delineate on the available seismic data and we have grouped them into a "superficial lobe area" (SL). SL is $200 \mathrm{~km}$ long at the minimum (not completely surveyed at its western boundary) and $60 \mathrm{~km}$ wide, representing a surface of more than 9000 $\mathrm{km}^{2}$. Maximum stacked thickness can locally reach approximately $100 \mathrm{~m}$.

\subsubsection{Undifferentiated unit packages}

In two areas, between well-identified channel-levee systems, we observed vertical or lateral stacking of several seismic units up to $216 \mathrm{~m}$ thick. Most of the seismic facies show similarities with the lobe facies identified at channel terminations (Fig. 13). Some of the seismic units exhibit shapes and facies more typical of channel axes, especially at the top of the packet of units. However, feeder channels and individual lobes were impossible to delineate and follow on our data because of the wide spacing of the acquisition grid, lack of resolution, and chaotic facies. To distinguish these thick clusters of vertically stacked undifferentiated channels and lobes from lobe complexes that are clusters of lobes related to one feeder channel, we choose to refer to these packets of units as "undifferentiated unit packages" (UPs).

Two such UPs are identified: UP1, the thickest one, is emplaced between Ax20 and Ax21 (Fig. 13); UP2 (Fig. 7) is emplaced between $A \times 35$ and $A \times 36$ and hides the upstream part of channels $A \times 28$ to $A \times 35$. 


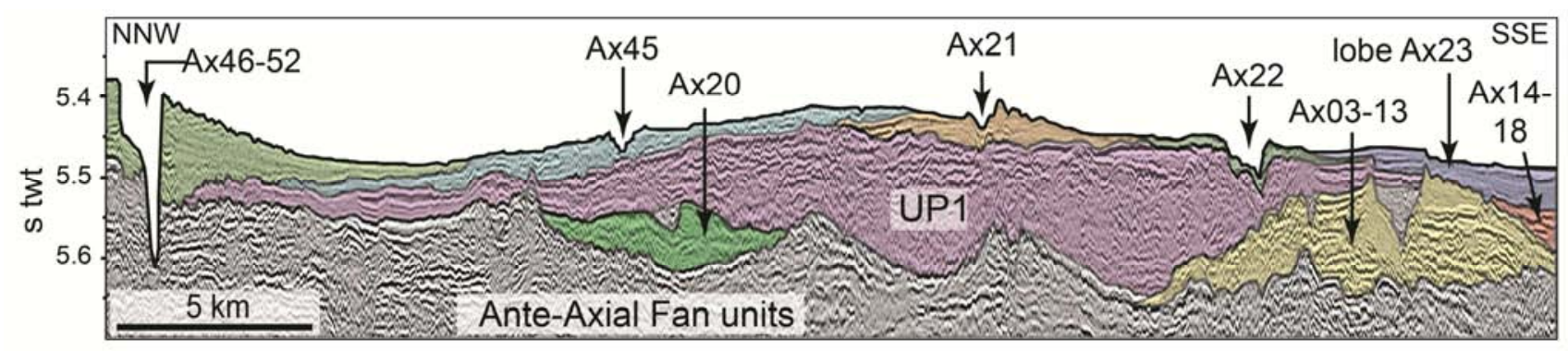

Fig. 13: A ninety-six channel seismic cross-section showing the undifferentiated unit package 1 (UP1). Same vertical scale as profiles in Fig. 11. Vertical Exaggeration: x26. Location of this cross-section in Fig. 7.

\subsection{Lobes size analysis}

In order to provide a consistent quantitative analysis of lobes, we measured the dimensions of the largest lobeshaped seismic units observed, which can correspond to the envelope of several sub-units. The dimensions and volumes of the lobes are provided in Supplementary Material A.

UPs represent very high volumes (up to $\sim 640 \mathrm{~km}^{3}$ ) but are uncommon in the Axial Fan. Therefore, they were not taken into consideration for the statistical analysis, even though we chose to plot them on the graphs.

\subsubsection{Lobe-shaped morpho-acoustic units: what are we looking at?}

Lobe-shaped morpho-acoustic units identified at the termination of Axial Fan channels were delineated based on multichannel air-gun seismic profiles with a vertical resolution of ca. $15 \mathrm{~m}$. Consequently the terminal units that we studied generally have thicknesses $>15 \mathrm{~m}$. The width/max-thickness ratio (Fig. 14) and the estimated volumes $\left(87 \%>100 \mathrm{~km}^{3}\right)$ show that these units are similar to the "lobe complexes" of Prélat et al. (2010). A lobe complex, as described in Prélat et al. (2009), is the highest hierarchic order of lobe depositional elements (including bed, bed-set, lobe element, lobe, and lobe complex, in order of low to high complexity). The smaller lobe-shaped units embedded in these lobe complexes, identified locally with higher-resolution seismic tools (sub-bottom profiler), such as those of the modern lobe complex (Babonneau, 2002; Savoye et al., 2000), correspond to the "lobes" in the terminology of Prélat et al. (2010). 
Therefore we will refer to our terminal objects as lobe complexes (single lobe-shaped unit and clusters of subunits) and lobes (sub-units) in agreement with Prélat et al. (2010, 2009). For easier understanding, a diagram is provided (Fig. 15) that gives the correlation between the adopted terminology (Prélat et al., 2010) and the objects described in 4.2 .

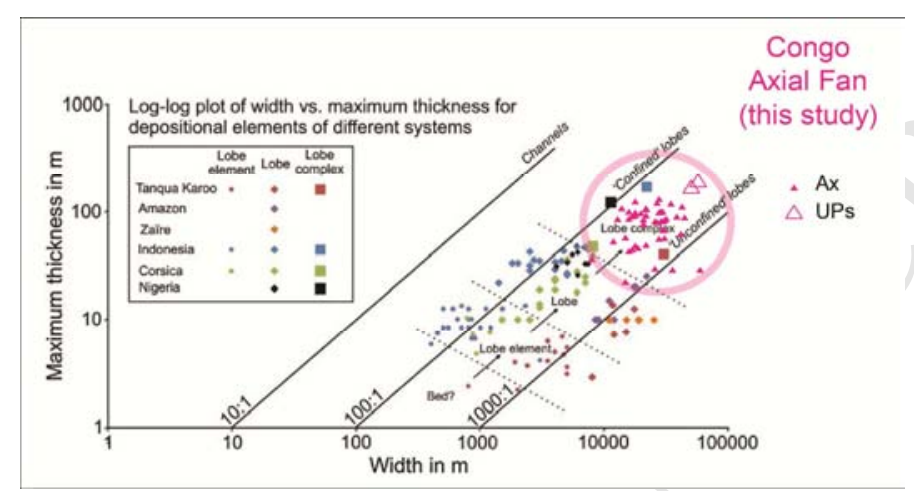

Fig. 14: Width vs. maximum thickness for lobe-shaped morpho-acoustic objects identified at the termination of channels in the Congo Axial Fan, plotted on the log-log plot for depositional elements of different systems of Prélat et al. (2010).

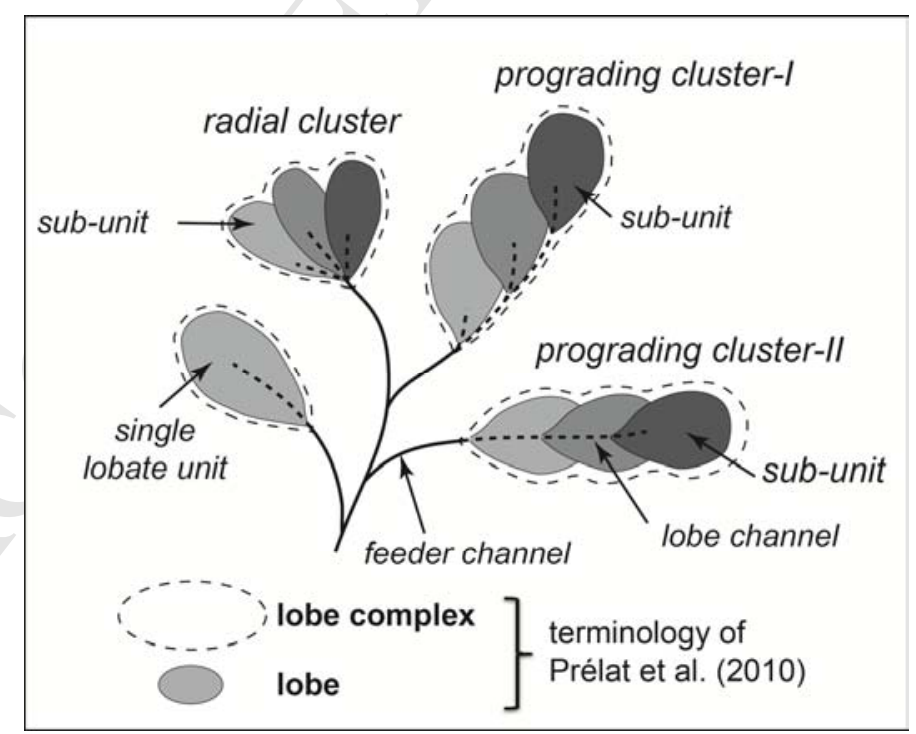

Fig. 15: Diagram illustrating the correlation between the terminology (lobe and lobe complex from Prélat et al. (2010) adopted for the following sections of the paper and the objects described (units, sub-units, clusters) in the previous section 4.2 . 


\subsubsection{Variability of the lobe complexes volumes and sizes}

Our results indicate that the calculated volumes show high variability (Fig. 16) ranging from $3 \mathrm{~km}^{3}$ to $196 \mathrm{~km}^{3}$, with $85 \%$ of the lobe complexes being $<100 \mathrm{~km}^{3}$. Volumes $>40 \mathrm{~km}^{3}$ are the most frequent (57\%) and among these $57 \%, 73 \%$ range from $40 \mathrm{~km}^{3}$ to $100 \mathrm{~km}^{3}$.

The cumulated volume of the lobe complexes identified in the Axial Fan represents $\sim 2600 \mathrm{~km}^{3}$, i.e. $30 \%$ of the total minimum volume of the fan $\left(8500 \mathrm{~km}^{3}\right.$, see section 4.2 .2$)$, the other $70 \%$ corresponding mainly to the addition of UPs, levees, channel fills, and HARP's.

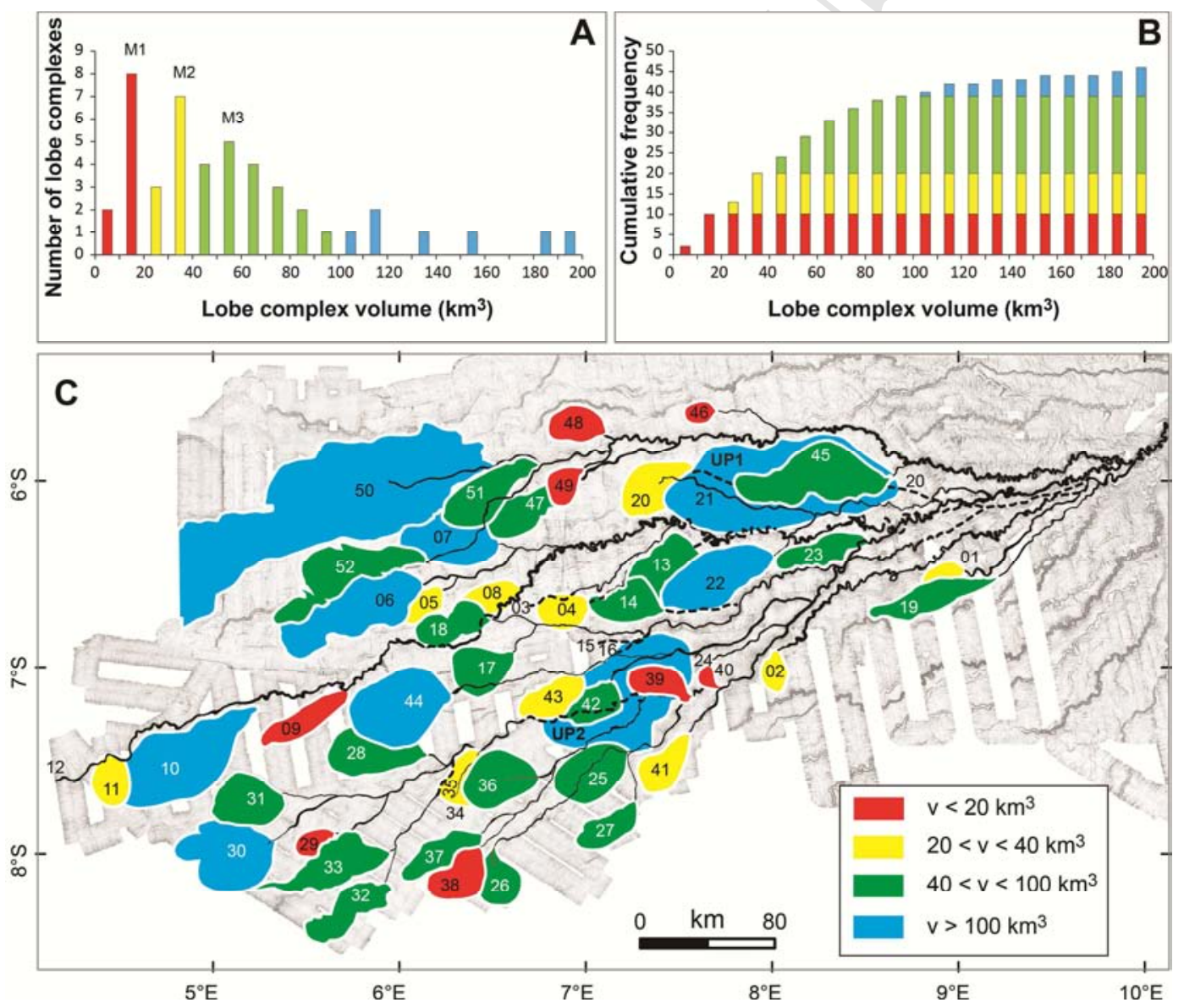

Fig. 16: Variability of lobe complex volume in the Congo Axial Fan. Colours correspond to groups of lobe complexes according to their volume. (A) Frequency distribution histrogram. The volumes are grouped into 3 main modes centered at 15,35 , and $55 \mathrm{~km}^{3}$ defining four main groups within which $22 \%$ are $<20 \mathrm{~km}^{3}, 22 \%$ 
range from 20 to $40 \mathrm{~km}^{3}, 4 \%$ range from 40 to $100 \mathrm{~km}^{3}$, and $15 \%$ are $>100 \mathrm{~km}^{3}$. (B) Cumulative frequency histogram. UPs are not considered in these plots. (C) Spatial distribution of the lobe complexes and UPs as a function of their volume.

The length to width ratio (L/W) (Fig. 17), which quantifies the shape of the lobe complexes, varies between 1.16 and 4.44. Maximum lengths and widths of the lobe complexes are limited to $100 \mathrm{~km}$ and $45 \mathrm{~km}$ respectively. SL (Ax50) and LPs are much greater than these boundaries. Lobe complexes having L/W $<2$ are the most frequent $(53 \%)$.

The variability of the L/W ratio is relatively low since a majority of values range between 1 and 2.4 , indicating that the lobe complexes are only slightly elongated as expected for deposition on an essentially flat and wide basin floor, free of major obstacles. The most elongated lobe complexes (L/W > 2.4, i.e.: Ax06, 09, 19, 23, 27, $32,33,37,45,50,52)$ occur for lengths greater than $40 \mathrm{~km}$ and correspond either to lobe complexes internally organized as type I progradational clusters (e.g. Ax52, Fig. 12B) or type II progradational clusters (e.g. Ax 32, 33, Fig. 12C) or to lobe complexes located upfan (e.g. Ax19, 23) and confined between channel-levee systems. Several lobe complexes (Ax04, 11, 13, 14, 17, 26, 30, 31, 34, 36, 40, 44, 46, 49) show shapes very close to the radial type $(1<\mathrm{L} / \mathrm{W}<1.5)$. They correlate with lobe complexes where radial stacking of lobes is observed (e.g. Ax30, Fig. 12A) or suspected by the presence of several lobe channels (e.g. Ax17, 31, 42). No lobe complex was observed to be of the wide type $(\mathrm{L} / \mathrm{W}<1)$ arguing for the absence of frontal obstacles high enough to prevent deposition or to deflect depositional flow.

There is no correlation between the shape (elongated or radial) and the volume of the lobe complexes (Fig. 17C). 

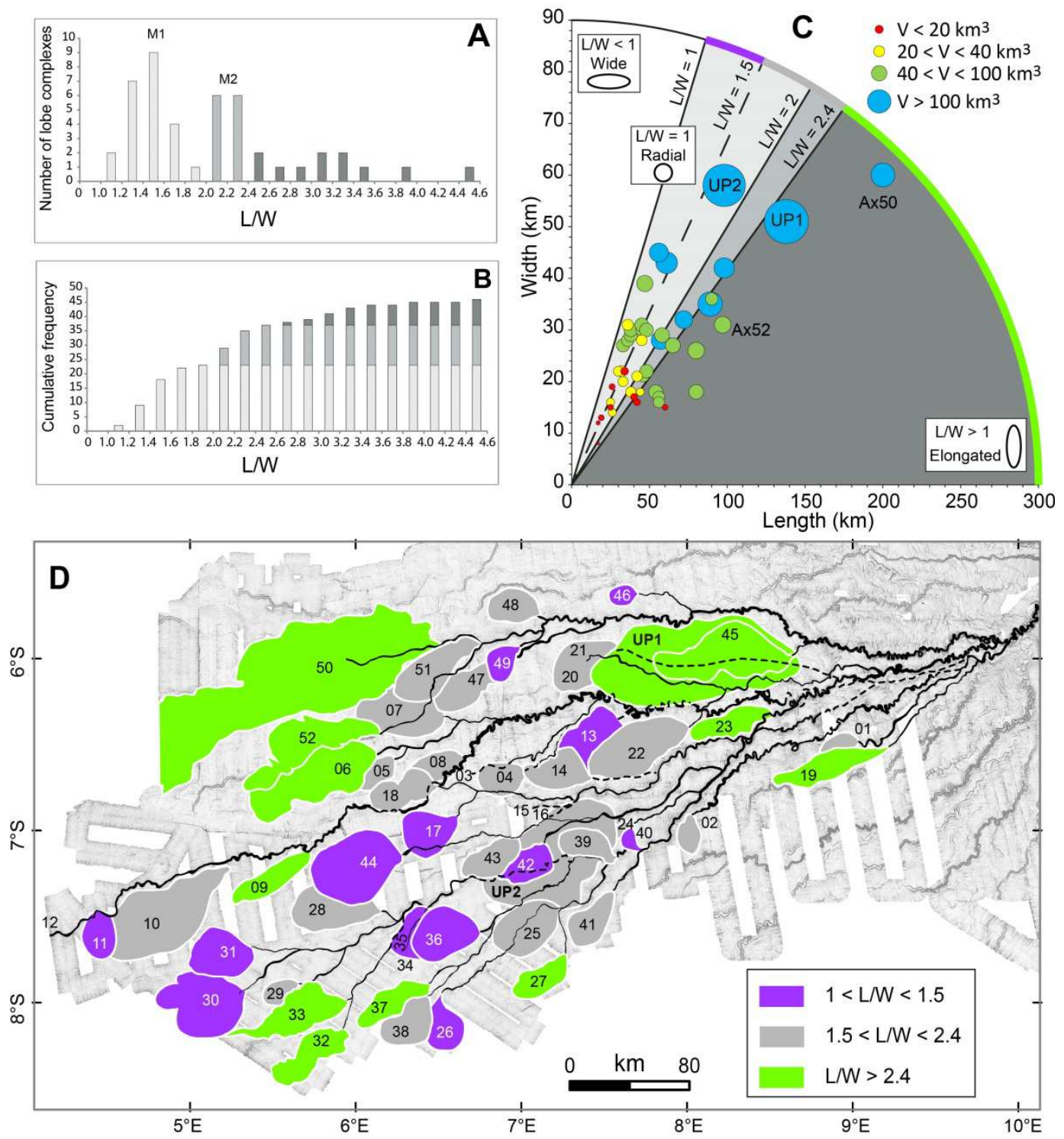

Fig. 17: Length to width ratio (L/W) of the Axial Fan lobe complexes and UPs. (A) Frequency distribution showing main modes centered on 1.5 and 2.2. (B) Cumulative frequency histogram. Light grey, grey, and dark grey correspond to groups of lobe complexes according to their L/W ratio. (C) Plot of length (L) vs width (W) with indication of volume $(\mathrm{V}) . \mathrm{V}$ is imaged as colored circles, the surface of which is a function of the volume value. UPs are not considered in A and B, but are plotted on the graph C. (D) Spatial distribution of lobe complexes and UPs as a function of L/W. 


\subsection{Architectural cycles}

In order to highlight the evolution of depocenters through time in the Congo Axial Fan, we plotted on a relative chronological (i.e. not dated) axis, the distance along the channel from a common reference point inside the canyon, to the entrance of the lobe complexes (representing the total channel length, $\mathrm{CL}$ ) and to the avulsion points (DA) (Fig. 18). We also plotted the avulsion length ( $\mathrm{AL}=\mathrm{CL}-\mathrm{DA})$ that represents the length along the channel of the newly created portion of the channel down from the avulsion point, and the number of avulsions ( $\mathrm{NbA}$ ) a channel is originating from (see 3.4 for details on the method used). Channel-levee systems that are taken into consideration in these diagrams are those at least 10-15 $\mathrm{m}$ thick (multichannel seismic vertical resolution) represented on the channel-lobe map as black or orange lines (Fig. 7). UPs represent a significant volume of sediment which may correspond to a significant duration, and have therefore been taken into consideration in the chronostratigraphic evolution of the fan. The feeder channels of UPs are not identified, so we measured an arbitrary minimum length defined as a straight line from the reference point to the UP apex. No avulsion point can be associated to these UPs and therefore neither DA nor AL is plotted for these units' accumulations. The measurements of the different parameters are provided in Supplementary Material B. The diagrams (Fig. 18) confirm the evolutionary trends observed by Marsset et al. (2009) at the scale of the whole Quaternary Congo Fan. In the Axial Fan, the evolution through time of parameters DA, CL, and NbA illustrates a repetitive architectural pattern that we call "architectural cycle". These cycles are constituted by the succession of downfan and upfan movements of the architectural parameters corresponding to alternative progradation and retrogradation of the depocenters.

Our work provides an up-to-date and more complete architectural evolution through time focused on the Axial Fan, which appears to be characterized by 4 main periods of progradation/retrogradation, (cycles $A$ to $D$ in order of decreasing age).

These architectural cycles are best constrained by the DA diagram (Fig. 18-5), because this parameter is not dependent on the uncertainties in length due to the identification or not of the terminal lobes. However, similar cycles are also observed in the CL diagram (Fig. 18-4). Cycles include variable numbers of channel-levee-lobe systems; the critical parameter we used for limiting the cycles is the maxima of retrogradation that corresponds to a small DA (Fig. 18-6). 
The shapes of the individualized cycles are variable, with (1) asymmetrical cycles (A and B) showing a longlasting progradation period followed by a rapid retrogradation phase ending with upfan (smallest DAs, i.e. < $250 \mathrm{~km}$ ) avulsions and abrupt abandonment of depocenters, and (2) a saw-toothed large bell-shaped cycle (C) characterized by gradual progradational and retrogradational phases. The end of the bell-shaped cycle shows, however, like the asymmetrical cycles, an abrupt retrogradation by an upfan avulsion. The saw-tooth pattern expresses higher order sub-cycles that can themselves be asymmetrical or bell-shaped. The deposition of UPs occurred during cycle $\mathrm{C}$, close to the beginning (UP1) and close to the middle (UP2).

These two types of cycles are representative of specific growth patterns of channel-levee-lobe systems. The symmetrical bell-shaped cycle C corresponds to prograding/expanding channel networks (Fig. 10B) and the asymmetrical cycles $A$ and $B$ dominantly correspond to prograding channel networks (Fig. 10A1).

The last cycle (D) apparently belongs to the asymmetrical cycle type. However, the lack of small DA at the end of this cycle leads us to consider it as an incomplete cycle, in agreement with the present-day activity of the youngest channel (Babonneau et al., 2004, 2002; Heezen et al., 1964; Khripounoff et al., 2003). This incompleteness prevents cycle D from being identified as a bell-shaped or asymmetrical type. However, channel network Ax45-52 that composes this last cycle shows a prograding growth pattern (Fig. 10A2), as observed for the asymmetrical cycles.

Cycle A also is incomplete, since the terminal parts of channel Ax12 are unknown (outside the survey area) However, should a prograding/expanding network develop at the terminal parts of channel Ax12, the asymmetrical shape of cycle A would probably remain because the next avulsion points would be positioned basinward from $A \times 11 / 12$ and $A \times 12 / 13$. The slope of the prograding phase would potentially decrease, with a possible saw-tooth pattern.

The evolution of the AL parameter is the same for all the cycles, showing higher ALs at the beginning of the cycle correlated to the shortest DA, followed by an irregular decrease (Fig. 18-6), highlighting that the lower portion of a channel created by an avulsion is progressively shorter during a sedimentary cycle. 
1

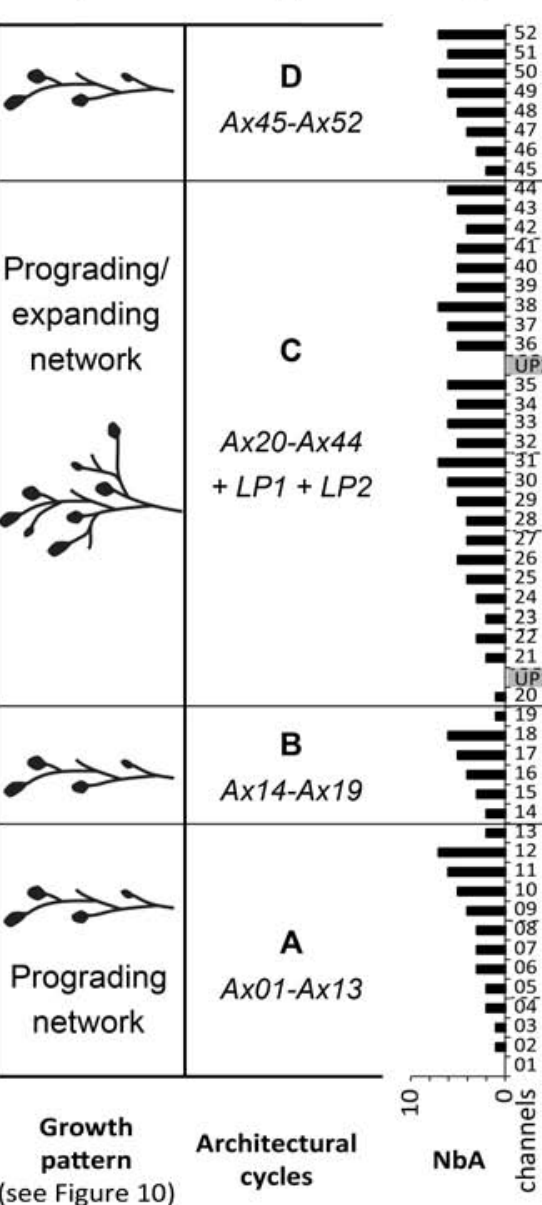

4

5

5

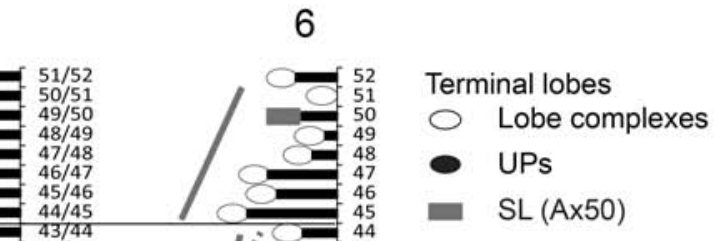

Architectural cycles

Asymmetrical

Bell-shaped

$\mathrm{AL}$ trends

Sub-cycles

$\because$ Asymmetrical

$\because$ Bell-shaped

$\because$ AL sub-trends

R Reference point

Fig. 18: Temporal evolution of the architectural parameters. See Fig. 5 and section 4.4 for details concerning the method used. (1) Growth pattern of channel networks (see Fig. 10). (2) Sedimentary cycles defined by the prograding/retrograding movements of depocenters. (3) Number of avulsion points per channel. (4) Channel lengths diagram. (5) Avulsion points diagram. (6) Avulsion lengths diagram. Refer to section 3.4 and Fig. 5 for method used to construct these diagrams.

The shortest AL tend to correlate with the longest DA (Fig. 19), indicating that when the avulsion occurs far away from the source point, the newly created portion is rather short, as expected from the decrease in the transport capacity of turbidity currents far from the input point. 


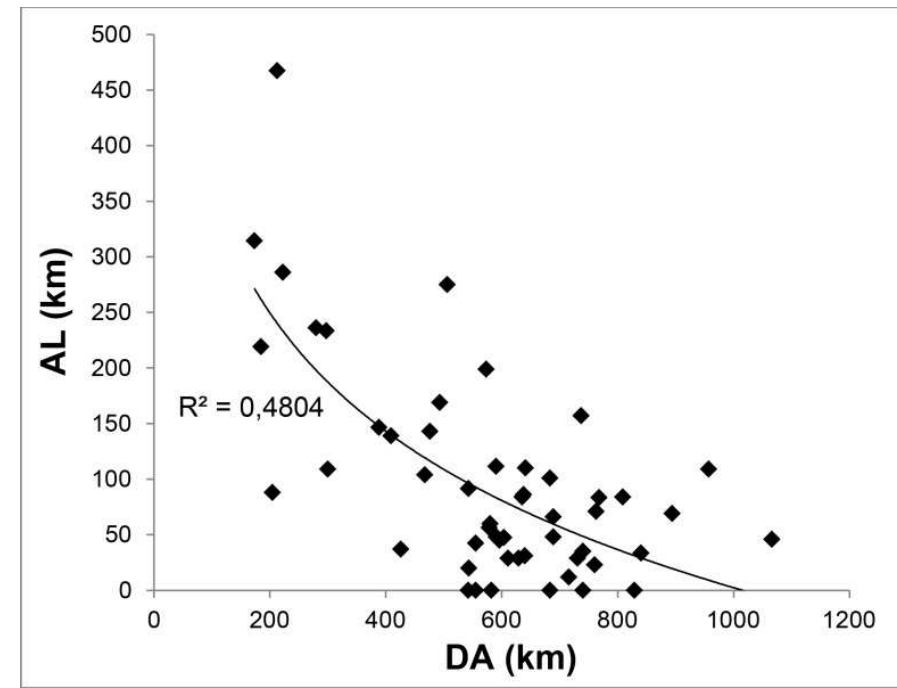

Fig. 19: Weak negative correlation $\left(R^{2}=0.4804\right)$ between the distances of the avulsion points $(D A)$ and the avulsion lengths on the new channel $(A L)$.

Both the volume and L/W ratio of the lobe complexes (Fig. 20) show a high variability and do not correlate with the sedimentary cycles. This lack of correlation suggests that the sizes and shapes of lobe complexes are controlled by processes of different origins, or by similar process but acting in a different manner from those controlling the architecture of the fan. Nevertheless, it should be noted that highest volumes of lobe complexes are limited to rather small ALs (Fig. 21) that tend to characterize the end of the cycles (Fig. 18). However, due to the high variability of the lobe complex volumes and ALs, no clear tendency can be deciphered. 


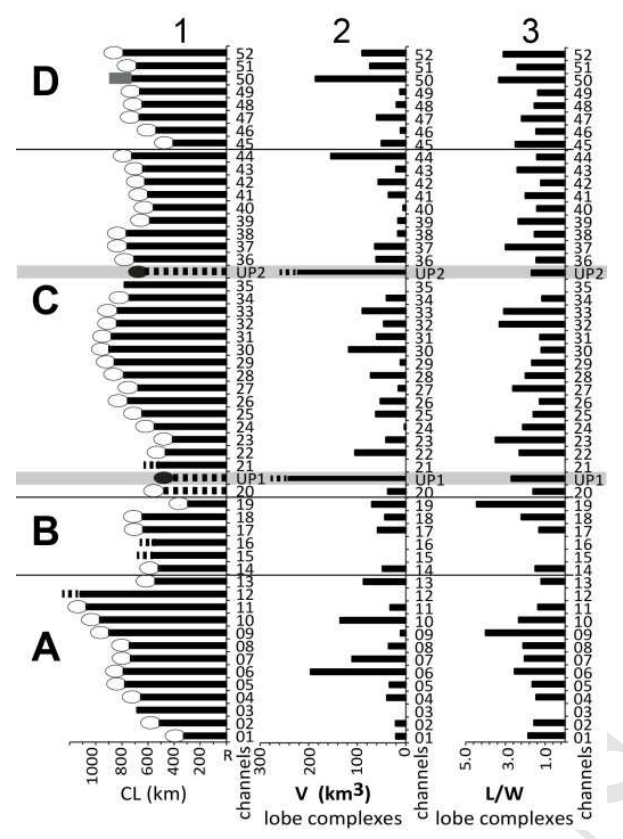

Fig. 20: Temporal evolution of UPs and lobe complex volume and LW ratio. (1) Channel length. $A$ to $E$ refer to architectural cycles. (2) Lobe complex volume. (3) Lobe complex Length to Width ratios. See Fig. 18 for legends.

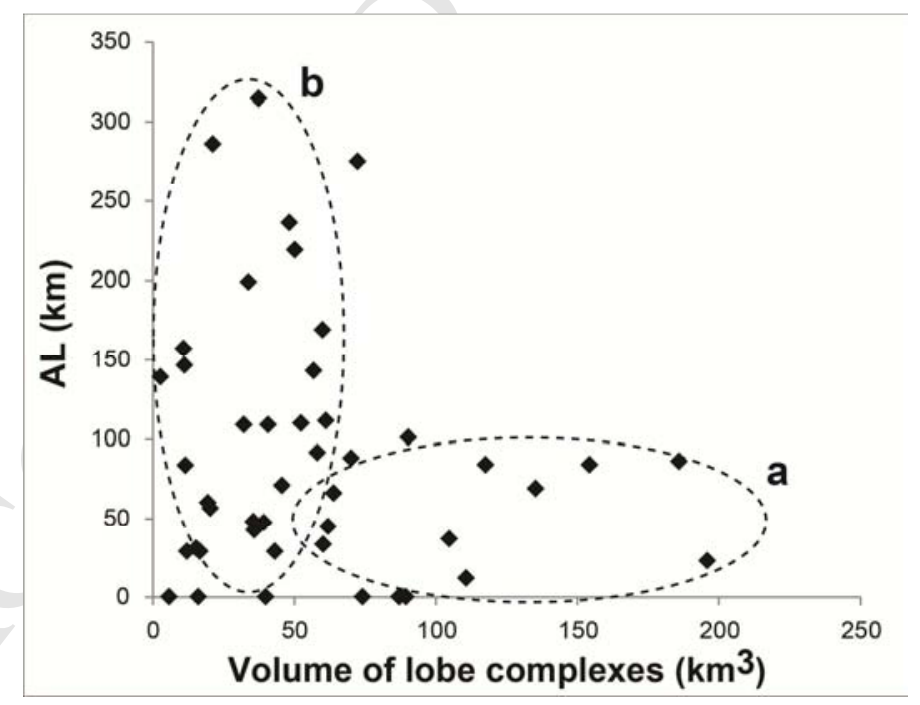

Fig. 21: Cross plot of lobe complex volume (V) vs channel Avulsion Length $(A L)$ showing a large variability but where two main populations of lobe complexes are identifiable, (a) $60<\mathrm{V}<200 \mathrm{~km}^{3}$ associated to short $\mathrm{AL}$ ( $\leq$ $100 \mathrm{~km})$ and (b) $\mathrm{V}<60 \mathrm{~km}^{3}$ associated to variable $\mathrm{AL}(0<\mathrm{AL}<320 \mathrm{~km})$. 


\subsection{Step-by-step evolution}

The step-by-step evolution of the fan is illustrated in Fig. 22. At the time of Axial Fan initiation, the Southern Fan was deeper than the Northern Fan (see section 4.2.2 and cross-section 1 in Fig. 9), The Axial Fan deposition started in the southern axis (Fig. 8A) with channels $\mathrm{Ax01}$ and $\mathrm{Ax02}$, before shifting northward where it developed the first prograding channel network ( $\mathrm{Ax03}$ to 13 ) that constitutes cycle $\mathrm{A}$ (Fig. 22A). The channels in cycle B (Fig. 22B), which also constitute a prograding network, were deposited between the channels of cycle A. Deposition ended with the short Ax19, parallel to and southward of Ax01, marking the retrograding period of cycle $\mathrm{B}$.

Cycle $\mathrm{C}$ deposited as a prograding/expanding channel network with a bell-shaped prograding/retrograding avulsion pattern, beginning with the deposition of channels Ax20-21 and UP1, mainly to the north of channels Ax03-13 of cycle $A$, and then progressively shifted southward (Ax22-23) until occupying the southern low axis (Ax24-35) close to Ax02 (Fig. 22C1). The next step is the deposition of UP2 (Fig. 22C2) covering the upfan part of Ax28-35 and then the deposition of channels and lobes Ax36-41 filling the space between Ax14-18 and Ax24-35.

Cycle D (Fig. 22D), including the presently active channel Ax52, was set up on the northern-most part of the Axial Fan with a purely prograding organization of the channel network. The cross-section shows that the channels of cycle D deposited atop a sedimentary high formed by the Northern Fan (Fig. 22D; see also Fig. 8B). This high was partly leveled out by the infilling of the nearby low by previous deposition (Ax20, UP1, Ax21) allowing the youngest channels to develop there. 

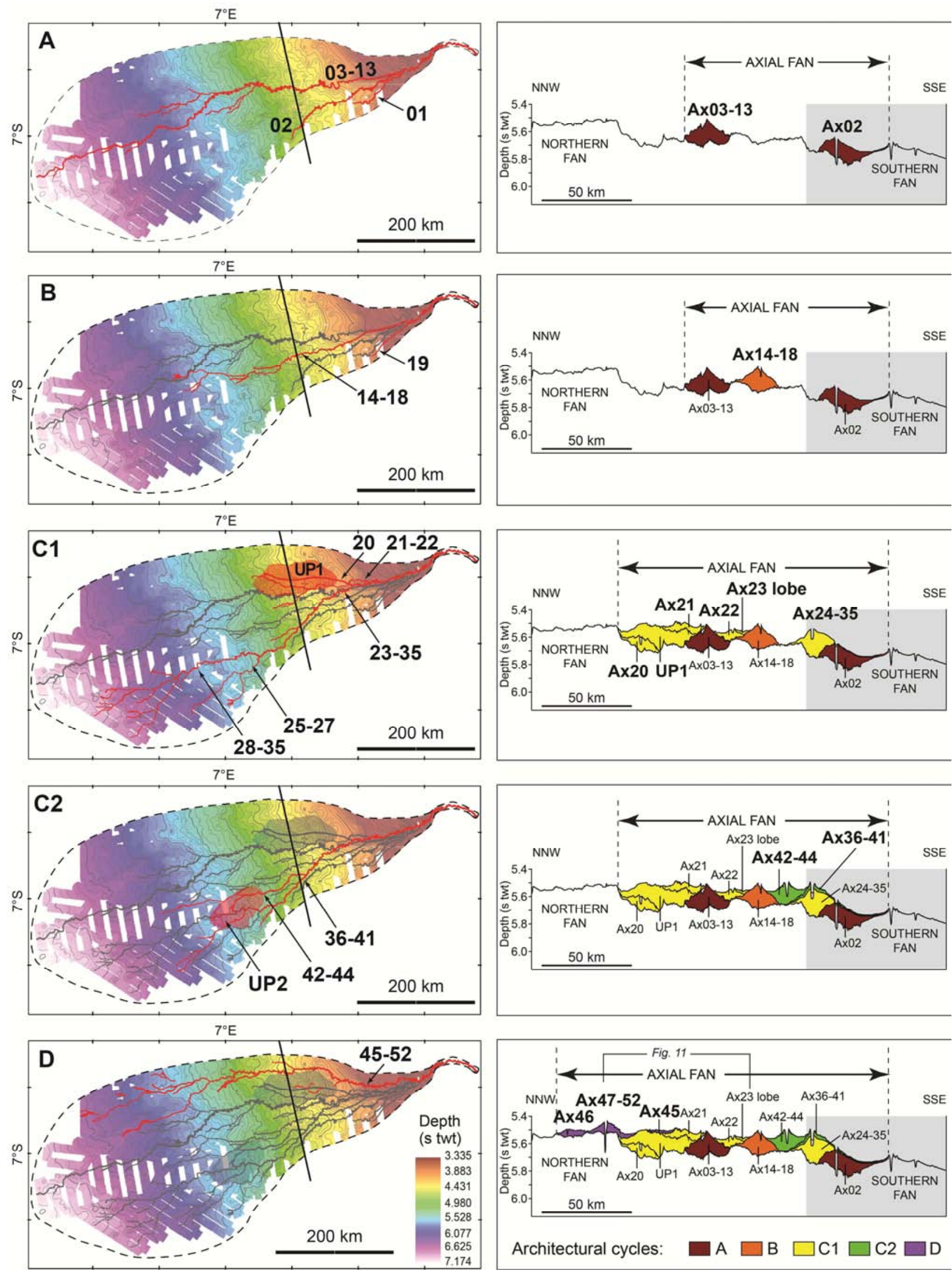
Fig. 22: Step by step architectural evolution of the Axial Fan (A to D refers to architectural cycles). For simple description, cycle C has been split into 2 stages C1 and C2. Left: Isochron map of the Axial Fan basement (see Fig.8A) showing the channels deposited at each cycle (red channels) and the previous channels (grey channels). Right: Line drawing (location on the maps to the left) of the depositional history of the different channels. Vertical Exaggeration: x50. Channels $A x 01$ and $A x 19$, located upstream from the cross-section are not visible here. Note that the deepening of the Southern Fan top surface is apparent and related to the inadequate orientation of the cross-section with respect to the Southern Fan. Nevertheless, cross-section 1 in Fig. 9 indicates that, upfan, the Southern Fan was deeper than the Northern Fan at the time of Axial Fan initiation. The greyed area on the cross-sections indicates the portion of the profile that is not strictly transverse to the channels, especially those of the Southern Fan.

\section{Discussion: Controls on the sedimentary evolution of the Axial Fan}

The architectural evolution of the Axial Fan is summarized in Fig. 23. Channel lengths (CL) and distances of avulsion (DA) are organized into successive synchronous bell-shaped or asymmetrical progradingretrograding cycles, associated to decreasing avulsion lengths $(A L)$. Smallest $D A$ and $C L$ and longest $A L$ characterize the minima of the cycles (i.e. the maxima of retrogradation, locus $R$ in Fig. 23), while longest DA and $\mathrm{CL}$ and shorter $\mathrm{AL}$ characterize the maxima of progradation ( $\mathrm{Pa}$ and $\mathrm{Pb}$ in Fig. 23). Asymmetrical cycles mainly consist of prograding channel networks and reflect the lack of sufficiently available lateral space to allow widespread divergence. In contrast, the bell-shaped cycle is made of well-developed prograding/expanding networks of channels, indicating low confinement during deposition. The cycles systematically terminate through abrupt retrogradation corresponding to very upfan channel avulsions. A saw-tooth pattern characterizes the bell-shaped cycle. This organization is linked to the development of secondary tree-like networks individualizing sub-cycles, themselves either asymmetrical or bell-shaped. The beginning of each sub-cycle is marked by high ALs (although always lower than the ones that bound the cycles) followed by an irregular decreasing trend.

Such successive prograding/retrograding architectural cycles as observed in the Axial Congo Fan since 200 ka were also described at a greater scale by Marsset et al. (2009) for the whole Late Quaternary turbidite 
system ( $800 \mathrm{ka}$ to present). A similar growth pattern was also observed at a lower scale, for example in the Karoo basin (South Africa) by Hodgson et al. (2006) and Van der Merwe et al. (2014).

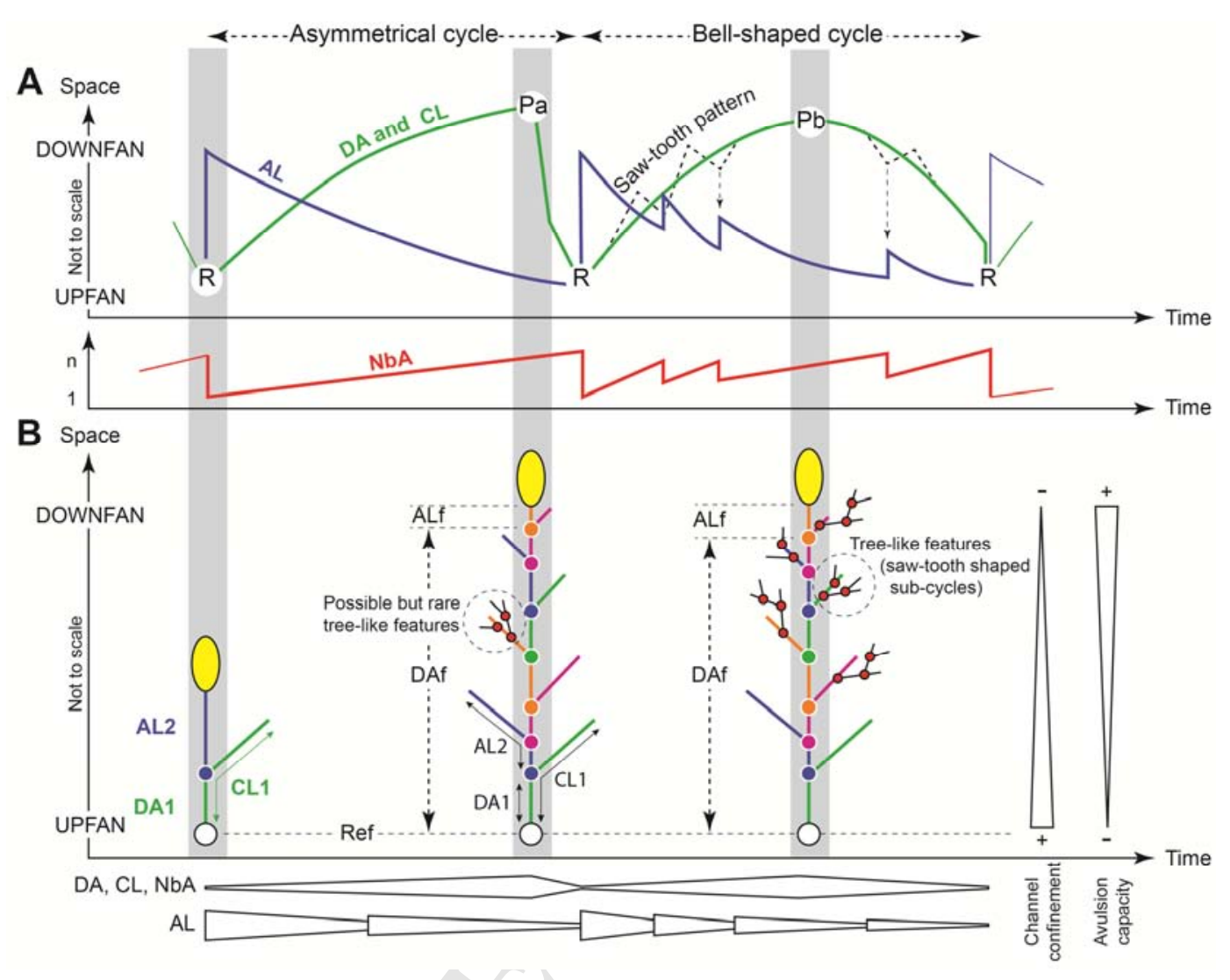

Fig. 23: Synthetic evolution through time and space of the architectural parameters of the Congo Axial Fan channel-lobe systems. (A) Schematic evolution of $\mathrm{DA}, \mathrm{CL}, \mathrm{AL}$, and $\mathrm{NbA}$ parameters. R: maxima of retrogradation; P: maxima of progradation of asymmetrical $(\mathrm{Pa})$ and bell-shaped $(\mathrm{Pb})$ cycles. (B) Schematic characteristics of channels at the beginning $(\mathrm{R})$ and maxima of progradation $(\mathrm{Pa}$ and $\mathrm{Pb})$ of the asymmetrical and bell-shaped cycles. Successive channels are represented as different colors. Colored points are the avulsion points, associated to the newly created portion of channel (AL). DAf and ALf are final values of DA and AL. Red dots refer to secondary avulsion points resulting in the tree-like architecture and saw-tooth subcycles. Yellow ellipsoids figure lobe complexes at the channel terminations. Ref: Reference point.

\section{Evidence of internal constraints by local topography}


Our study highlights the importance of the seabed topography control, revealed by the step-by-step evolution of channel-levee-lobe systems (Fig. 22). This evolution points to the importance of inherited topography as a primary control that, in most cases, explains the emplacement of the channels in topographic lows. This seems to be the case for most distal channels that expand laterally on a very flat seafloor (e.g. distal parts of channels Ax28-35 in Fig. 22C), or that acquire parallel courses when confined by nearby channels or lobes (e.g. distal channels of the Ax25-27, Ax36-41, and Ax42-44 sets in Fig. 20C and D). This is also the case for UP1 that infilled a topographic low on the northern side of channels Ax01-Ax19. In contrast, the thinness of fan deposits related to channels Ax45-52 (Fig. $8 \mathrm{C}$ ), and the erosive nature of the youngest channel, probably attest to the limited space available for deposition on this part of the basin.

The shapes of lobe complexes (L/W ratio) show further evidence of a local topographic control (Fig. 17) as observed in other fans (e.g. Jegou et al., 2008; Prélat et al., 2010), with elongated lobes occurring upfan where lateral space is restricted or downfan in association with a prograding stacking pattern that suggests a control by nearby channel or lobe topographies. For instance, lobe complex Ax06 prevented the southward development of Ax52, and therefore forced the lobes to shift to the North.

However, the detailed evolution of channel emplacement (Fig. 22) shows that the relationship with the evolution of available space is not so simple. In several cases, a channel avulsion occurred before the infill of the available space. For example, the cross-section of Fig. 22A shows that the area occupied by Ax02 was not fully filled when the depocentre shifted northwards to Ax03-13. The position of Ax14-18, which shifted to the south of the Ax03-13 channel network, is also not fully understood, since the seafloor to the north of this previous channel network was deeper (cross section in Fig. 22B). These cases suggest that topographic compensation is not the only factor that controls a channel avulsion. In addition, the last group of channels (Ax45 to Ax52, Fig. 22E) developed on a topographic high formed by the deposits of the Northern Fan, even though space was available in the area between Ax21 and Ax42-44 and south of channel Ax02 (Fig. 9, crosssections 1 and 2). In this case, the topographic control probably was stronger at the apex of the fan where the avulsion occured. Upfan avulsions shift the turbidity current toward the nearest local bathymetric lows (i.e. the local base of levee outerbank and the interchannel area). The locus and direction of the avulsion therefore determine the future confinement and channel pathways as a function of the new local topography, the new 
channel following the greatest local slope. Consequently, the location of the avulsions and the surrounding slope gradients appear as crucial controlling parameters for channel-levee-lobe evolution.

\section{Evidence of exceptional events during the construction of the Axial Fan}

The length of a channel depends on the interplay of numerous parameters through time and space. These parameters include the transport efficiency of the flow, governed principally by the sand/mud ratio of the sediment content (Gladstone et al., 1998; Kneller, 2003; Mutti and Ricci Lucchi, 1972; Reading and Richards, 1994; Salaheldin et al., 2000), the velocity of the current (Hjulstrom, 1939), local gradient changes, sinuosity, and confinement by lateral levees (e.g. Alexander and Morris, 1994; Kneller, 1995). These parameters are combined together to define the transport capacity of the currents.

In the case of equilibrium, a channel is characterized by a down channel decrease in levee height and channel depth, and therefore a decrease in the confinement of the currents flowing inside. For example, the height of the youngest channel of the Congo Fan evolves from $250 \mathrm{~m}$ (including the central erosive thalweg) in the area of our most upfan avulsion to less than $50 \mathrm{~m}$ at the entry of the lobe complex, about $1000 \mathrm{~km}$ away from the canyon head (Babonneau, 2002). The decrease in confinement leads to an increase in the possibility of the turbidity currents overspilling, as observed by the downfan increase in sedimentation rates on levees of the present-day Congo channel (Savoye et al., 2009). Increased overspill results in the loss of the fine-grained part of the current and correlative thinning of the flow and an increase in the sand/mud ratio (Kneller and McCaffrey, 1999; McCaffrey and Kneller, 2004), which can ultimately lead to a decrease in the transport efficiency. In addition, the slope profile of a channel decreases down channel (e.g. Babonneau, 2002; Jégou, 2008; Kneller, 2003), leading to a progressive decrease in the current velocity (Kneller, 1995). The decrease in velocity, transport efficiency, and confinement leads to the down channel decrease in transport capacity. The complete loss of confinement at the termination of the channels results in the deposition of lobes and lobe complexes.

Distance to avulsion points: a proxy of the capacity of the currents to initiate an avulsion This morphological evolution also determines the ease of which the avulsions may be achieved. 
Upfan avulsions, where the levees are high and the channel is deep, are more difficult and therefore probably less frequent (Figure 24A). To be achieved, upfan avulsions need exceptional conditions in order to allow the current to escape and create a new channel, such as: (i) levee instability and breaching promoted by slope increase with time (e.g. Twichell et al., 1996), channel sinuosity(e.g. Babonneau et al., 2002), low cohesion of deposits (e.g. Kolla, 2007), or preexisting weakness under the levee (Ortiz-Karpf et al., 2015) (ii) occurrence of turbidity currents with volumes greater than usual (i.e. volume and thickness much greater than the levee height where the avulsion occurs) (Pirmez and Imran, 2003), in relation to a strong increase in fluvial discharge, and (iii) decreasing channel depth until usual turbidity currents can escape (e.g. Kolla, 2007). Upfan avulsions by channel floor backfilling and aggradation have been described by Turakiewicz (2004) in the Northern Congo Fan, by Armitage et al. (2012) in the Niger Delta, and by Dorrell et al. (2015) in the Amazon Fan. These backfilling flow conditions can occur when turbidity currents have low efficiency (high sand/mud ratio). In the absence of a modification of the base level, the change from the erosive to aggrading regime inside the channel is related to a decrease in volume, density, or transport efficiency of the turbidity currents (Armitage et al., 2012; Kneller, 2003).
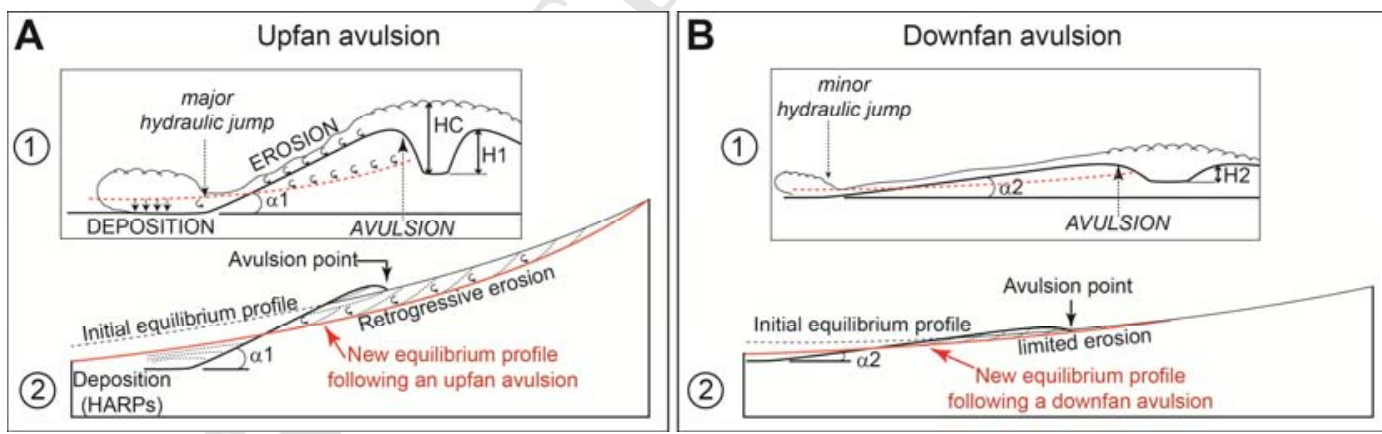

Fig. 24: Upfan-downfan morphological evolution and morphological changes following an avulsion upfan (A) and downfan (B). (1) Conceptual cross-sections at the avulsions points. $\mathrm{HC}, \mathrm{H} 1$, and $\mathrm{H} 2$ are the current thickness and upfan and downfan levee heights, respectively. $\alpha 1$ and $\alpha 2$ are the slope gradient of the upfan and downfan levees, respectively ( $\alpha 1>\alpha 2$ ). (2) Conceptual dip sections (inspired from Pirmez et al., 2000) illustrating the severe morphological changes generated by avulsion in upfan regions and the low modifications in downfan domains. 
In the Congo Axial Fan, we believe that levee instability, which is not commonly observed (Babonneau, 2002), is not a major factor for the upfan avulsions highlighted by the short DA ( $D A<250 \mathrm{~km})$.

We suggest that the four exceptional avulsions resulted from the two other major causes, in relation to relative sea-level change and/or climatic change in the Congo catchment (Fig. 25): (i) enhanced sediment flux from the Congo River able to generate unusually large magnitude turbidity currents, and/or (ii) enrichment of inputs with coarse-grained material, which decreases the transport efficiency of the turbidity currents and allows the channels to backfill. Periodic collapse in the canyon of sand bars accumulated in the Congo estuary (Moguedet, 1988) is a possible mechanism that can abruptly increase the sand/mud ratio of the inputs and generate unusually low-efficiency turbidity currents. These hypothesized low-efficiency currents should, however, remain efficient enough to reach a distance of $480 \mathrm{~km}(D A=250 \mathrm{~km})$ from the canyon head, where the upfan avulsions occur.

In contrast, because of lower confinement (Fig. 24B), downfan avulsions are easier and more frequent. We suggest that the variations of the DA parameter in downfan areas (location and timing of avulsions) are probably more subject to control by local topography (local slope changes, channel sinuosity, etc). 


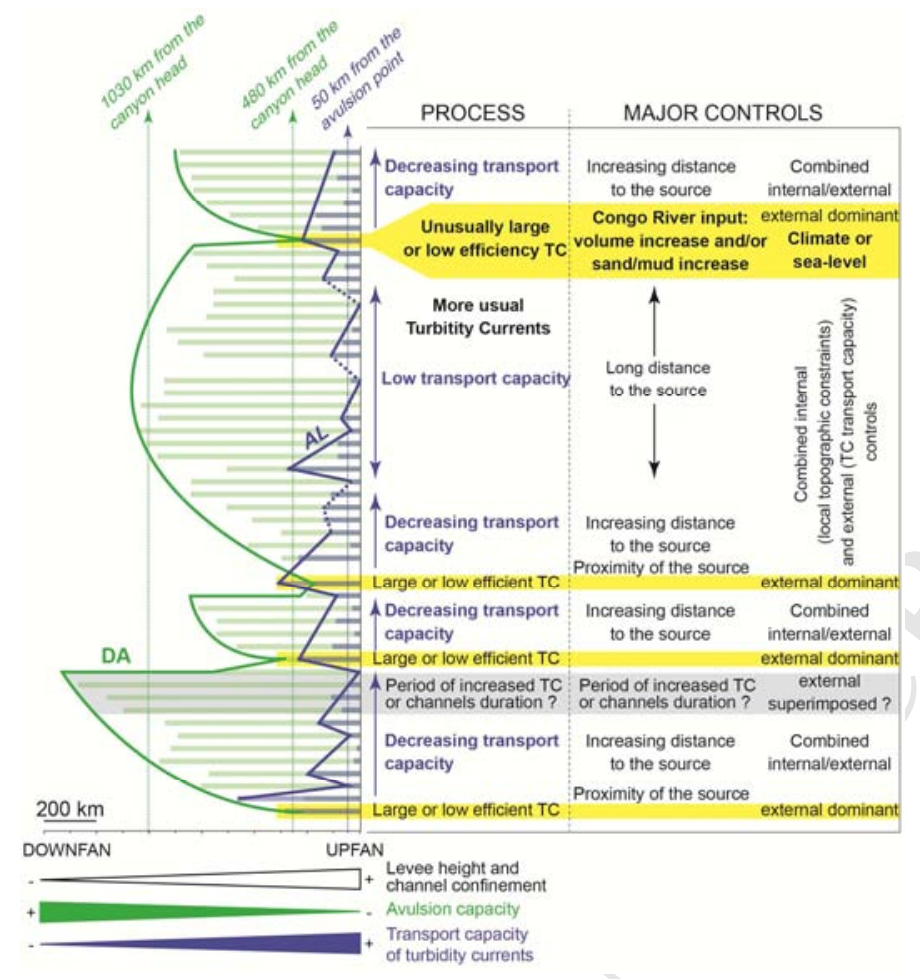

Fig. 25: Factors controlling the sedimentary evolution of the Axial Fan as deduced from the evolution of the architectural parameters. Yellow lines refer to exceptional climatic or sea-level related events provoking upfan avulsions (as explained for the youngest event). DA: Distance of avulsion. AL: Avulsion length. TC: Turbidity currents.

Avulsion length: a proxy of the transport capacity of the currents

The AL parameter enables a discussion on the portion of the channel that was created following an avulsion and the role of topographical modifications generated by this avulsion.

The avulsion process provokes severe local morphological reshaping (e.g. Pirmez et al., 2000), especially when the avulsion occurs upfan (Fig. 24). After a levee breach the downstream slope is much higher than the slope upstream, hence the avulsions provoke abrupt breaks in slope, disrupting the equilibrium state of the channel. In order to acquire a new equilibrium profile, both retrogressive erosion in the channel and deposition downstream occur (Fig. 24A2). Erosion of the fine levee sediments and coarser channel-fill sediments modifies the sand/mud ratio of the sediment load in the turbidity current. In addition, an avulsion provokes hydrodynamic modification of the turbidity current as it passes from being confined upstream to being 
unconfined downstream from the avulsion point, and, together with slope variations, subsequently introduces current velocity changes. The new channel-levee (and the associated confinement) only begins to grow and prograde when the equilibrium state is re-established (e.g. Babonneau, 2002; Flood et al., 1991; Flood and Piper, 1997; Lopez, 2001; Pirmez et al., 2000).

The length of a channel downstream from the avulsion point is the result of complicated interactions between several parameters: (i) the duration of the channel, which depends on the timing of the subsequent avulsion, (ii) the turbidity current volume and frequency during the duration of the channel linked to the inputs from the Congo River, (iii) the intrinsic parameters of the turbidity currents (transport efficiency, velocity ...) which evolve differently depending on the location of the avulsion, and (iv) the local topographical changes along the new channel path, also dependent on the location of the avulsion.

We suggest that AL, which indicates the most distal area where turbidity currents are able to deposit sediments through time, can be considered as a general proxy of the transport capacity of the currents that were travelling inside the channels, and therefore are controlled partly by internal factors (channel confinement, morphologies and slopes, avulsion frequency) and partly by external factors (turbidity current frequency, volume and composition of sedimentary inputs from the source).

It is supposed that, upfan (long AL, infrequent avulsions), the effect of severe morphological modifications (Fig. 24A) generated by the avulsions will be more significant than other parameters in modifying turbidity current behavior. In contrast, more downfan (short AL, more frequent avulsions), the avulsions provoke minor changes in the equilibrium profile (Fig. 24B) and therefore the turbidity current dynamics remain unchanged. In this case, the avulsion frequency will be the dominant parameter in controlling the new channel length.

At the Axial Fan scale, the decreasing evolution of AL, from the beginning to the end of the architectural cycles and sub-cycles, could reflect the decreasing transport capacity of the turbidity currents combined with the decrease in the regional slope downfan and/or decrease in the lifespan of the channels (increase in avulsion frequency).

High ALs at the beginning of the cycles and sub-cycles suggest that upfan avulsions are followed by currents with increased transport capacity, in agreement with our interpretation of the upfan avulsions. 
It should be noted that the longest channel lengths, which define the maxima of progradation of each cycle, are relatively constant, approximately $800-900 \mathrm{~km}$ from the reference point (i.e. $1030-1130 \mathrm{~km}$ from the canyon head or Congo River mouth) (Fig. 18), arguing for a threshold effect (maximum length reachable by usual turbidity currents as a function of all the previously mentioned parameters) as one of the primary controls of the architectural evolution of the Axial Fan. Only a set of 4 channels (Ax09-12) overcome this threshold value and may therefore attest to a period when turbidity currents had an unusually high transport capacity (or, long channel duration or high frequency of turbidity currents), possibly in relation to a source effect originating from climatic changes in the Congo basin or sea-level changes on the shelf.

\section{Conclusions}

Recent geophysical data added to an existing large data set permitted analysis of 52 channel-levee systems visible at the seafloor of the most recent part of the Congo turbidite system, i.e. the Axial Fan ( 200 ka to present). The main characteristics of the Axial Fan, observed through the filter of seismic resolution, are:

- Channel lengths range from $300 \mathrm{~km}$ to more than $1000 \mathrm{~km}$ from the reference point (i.e. 530 to 1230 $\mathrm{km}$ from the canyon head and Congo River mouth). The very long channel-levee-lobe systems attest to the ability of density currents travelling inside these channels to deliver sediment to the deepest part of the basin.

- Most of the channels have terminal lobe-shaped seismic units. Comparison of the dimensions of these units (size and volume) with the dimensions mentioned in the analysis by Prélat et al. (2010) allows classification of the identified units as "lobe complexes" (terminology of Prélat et al. (2009). Sub-units stacked in clusters can be classified as "lobes". Some of the lobe complexes show internal radial or prograding stacking patterns, reflecting probable contrasted topographic constraints affecting distal deposition.

- The majority of lobe complexes are only slightly elongated ( $\mathrm{L} / \mathrm{W}<2.4)$, attesting to moderate lateral topographic constraints during their deposition. However, some of the lobe complexes show L/W > 2.4. Most of these lobe complexes are located upfan, as can be expected in areas where there are more 
pronounced topographic constraints due to channels spatially close to each other. Other lobe complexes with $L / W>2.4$ are located downfan, i.e. where more space is available for deposition, and attest to local confinement, possibly by ante-Axial Fan seabed morphology.

- Volumes of lobe complexes range from $3 \mathrm{~km}^{3}$ to $196 \mathrm{~km}^{3}$, with $85 \%$ of the lobe complexes being $<100$ $\mathrm{km}^{3}$. They are highly variable in time and space, and no particular trend can be pointed out. The minimum cumulative volume of the lobe complexes reaches $2600 \mathrm{~km}^{3}$, and therefore represents a significant part of the Axial Fan sediments, i.e. up to $30 \%$ of the total minimum volume of the fan (8500 $\mathrm{km}^{3}$ ). The remaining $70 \%$ corresponds mainly to the addition of levees, channel fills, HARP's, and undifferentiated channels and lobes packages (UP)

- The architectural evolution of the Axial Fan points to a clear, but not simple, control of the inherited topography (older channel-levees) on the sedimentation. The morphological modifications generated by avulsions also appear as a critical controlling parameter, especially when they occur upfan.

- The measurements of architectural parameters (mainly channel lengths and distances to avulsion points) give constrains on the Axial Fan's sedimentary evolution since $200 \mathrm{ka}$ and outline a succession of periods of increasing/decreasing channel lengths and basinward/landward migrations of avulsion points. These periods represent successive prograding/retrograding architectural cycles, as described by Marsset et al. (2009) for the whole Late Quaternary Congo Turbidite System ( 800 ka to present). Architectural cycles are either symmetrical saw-toothed and bell-shaped, with progressive progadation and retrogadation phases $(\mathrm{C})$, or asymmetrical with long-lasting progradation phases and abrupt retrogradation phases that are linked to channel avulsions occurring up on the fan (A, B). The type of the last cycle (D) is not ascribed since this cycle is not terminated (the fan is currently active).

- The distance to avulsion points is considered as a proxy of the capacity of the turbidity currents to initiate an avulsion. Due to the morphological evolution of the channel-levee systems, avulsions are easier downfan than upfan. The lack of levee collapse observations indicates that levee instability increasing through time is not a factor causing upfan avulsion. The four most upfan avulsions identified are therefore considered to be exceptional events of enhanced turbidity current volumes and energy, probably caused by dramatic increases of sedimentary input from the Congo River and/or decreased 
transport efficiency of the currents, possibly in relation to a collapse of the sand bars (increase in sand/mud ratio) of the Congo estuary in the canyon head. These exceptional events would thus be controlled by allogenic factors, such as climate or sea-level changes.

- The avulsion length parameter is considered as a proxy of the transport capacity of the turbidity currents that constructed the channels. Each cycle is characterized by a general decreasing trend of the transport capacity, partly in relation to increasing distance from the source, and partly controlled by the avulsion process.

Our qualitative and quantitative study of morphological parameters of lobes and channels therefore points to the critical role of local topography as a major factor controlling the architecture of the Congo Axial Fan, especially upfan. However the evolution of the architecture revealed exceptional events of upfan channel avulsions that are suggested to relate to external factors (sea-level, climate change) able to drastically increase or coarsen the sediment supply to the fan. 


\section{ACKNOWLEDGMENTS}

This work was supported financially by the French program Action MARGES of INSU and by TOTAL and was undertaken with the full support of "Laboratoire d'Excellence" LabexMER (ANR-10-LABX-19). Marie Picot's PhD was co-funded by IFREMER and TOTAL.

We thank the Captains and crews of the research vessels where the data were acquired between 1998 and 2011 (R/V L'Atalante, Le Pourquoi Pas? and Le Suroît, from Ifremer fleet) and the technicians from Genavir who ensured the acquisition of the geophysical data. A. Gaillot and D. Pierre (Ifremer) processed the Reprezaï multibeam data. Y. Thomas, P. Dupont, M. Montferrand, P. Woerter, R. Silva Jacinto (Ifremer), M. Robin, C. Répin, A. Mazuel (University of Brest) and F. Pattier (University of Perpignan) processed the Reprezaï seismic data on-board. We thank J.M. Augustin (Ifremer) for Sonarscope software training and kind help. This manuscript has also benefited from constructive suggestions by M. Rabineau (UMR CNRS 6538). K. Kovacs provided English editing services. Seismic data were analyzed using Kingdom Suite software, kindly made available to UBO by IHS. Pr. D. Hodgson and associate editor (T. Hadlari) are kindly thanked for their detailed reviews and suggestions that greatly strengthened the paper.

This work is a contribution to UMR 6538 (Laboratoire Domaines Océaniques) and to IFREMER project PJ2207 "Systèmes et Evolutions Sédimentaires". 


\section{FIGURE CAPTIONS}

Fig. 1: (A) The Congo sedimentary system from source (Congo River and its catchment) to sink (Quaternary turbidite system). (B) Channel depth profile of the Congo River (light blue) and its tributaries (from Devroey, 1941 and Moguedet, 1988) and of the Congo canyon and channel (modified from Babonneau et al., 2005). Vertical exaggeration $\times 370$.

Fig. 2: Distribution of the channel-lobe systems in the Quaternary Congo turbidite system (modified from Marsset et al., 2009). (A) Channel-lobe map. Grey lobe-shaped features are terminal lobes. (B) The three individual fans.

Fig. 3: (A) Principle of the polynomial surface-compensated bathymetry, showing the enhancement of the relief obtained with processing the original DTM by subtracting the polynomial surface calculated by Sonarscope software (developed by Ifremer). (B) Application to the Congo turbidite system. Left: Original DTM which clearly shows the channel network, but fails to image faint morphological variations. Right: Relief map: bathymetric map corrected from the general slope, which better illustrates the relief variations in the basin. Note the apparent "thickening" at the western and southeastern part of the map, at the limit of the grid, probably linked to a decrease in slope. Base map: ETOPO1 bathymetry (Amante and Eakins, 2008).

Fig. 4: Location of seismic data acquired during GUINESS, ZAÏANGO, and REPREZAÏ surveys, and location of the Axial Fan (grey area). Base map: slope map of the ETOPO1 bathymetry (Amante and Eakins, 2008).

Fig. 5: Principles of measurements of the architectural parameters with CL (Channel Length), DA (Distance of Avulsion), $A L$ (Avulsion Length), where $C L=D A+A L$. (A) Principle of superposition that was used to establish the relative chronology of channels (channels 1 to 4 in order of decreasing age). (B) Schematic channel network illustrating the measured distances. DA1/2, distance of the avulsion point $1 / 2$ (from channel 1 to 
channel 2) to the reference point R; CL1, along-channel distance from the inlet of the lobe to the reference point $R$ (total length of channel 1 ). (C) Construction of the diagrams. Note that the vertical scale is a relative time scale. Number of avulsions diagram $(\mathrm{NbA})$ : for each channel, the total number of avulsions along its course. Avulsion points diagrams (DA): the avulsion point $1 / 2$ is attributed to channel 2. Channel-lengths diagram $(C L)$ : the grey lobe-shaped features are terminal lobes, indicating that the plotted distance is the true length of the channel; dashed lines indicate that the channel could be longer. Avulsion length diagram (AL): length of the newly created channel following the avulsion, from the avulsion point (DA) to the inlet of the lobe. Note that for the first channel, AL cannot be defined as there is no avulsion point. Modified from Marsset et al. (2009).

Fig. 6: Topography of the Axial Congo Fan. (A) Relief map (see 3.1 about the processing of bathymetric data). Dashed line: approximate boundaries of the Axial Fan. Dotted lines: boundaries of the main depositional axes (Northern and Southern channels) highlighted by yellow to light green colors. These depositional axes are separated by a topographic low (dark blue to light blue) where channels are observable (Central channels) (B) Serial bathymetric cross-sections from the apex to the distal parts of the Axial fan (sections are in s twt to be easily compared with those presented in Fig. 9). NC: northern channels; CC: central channels; SC: southern channels. Vertical Exaggeration: x50.

Fig. 7: New channel-lobes map of the Late Quaternary Axial Congo Fan established from bathymetric and seismic data (multichannel seismic and Sub-Bottom Profiler data). Chronologically referenced channels, terminal lobes, avulsions points and UPs are drawn on the slope map of the whole fan. Present-day channel and lobes (simplified from Babonneau, 2002 and Bonnel, 2005) are in orange. Note the reference point used for measurements. The location of the seismic sections of Fig. 11 and 13 are indicated as black straight lines.

Fig. 8: Paleotopography of the Axial Fan basement and thickness map of the Fan. (A) Isochron map (in s twt) of the basement showing low topographic axes: NA (northern axis), CA (central axis), SA (southern axis). (B) 
Relief map (in s twt) of the Axial Fan basal surface. (C) Isopach map (in s twt): the lack of close reference to the basal surface of the Axial Fan in the most distal area leads to greater uncertainties. The black lines correspond to the cross-sections shown in Fig.9.

Fig. 9: Serial cross-sections from upfan (section 1) to downfan (section 4) of the Axial Fan. Same scale for each cross-section. Dashed lines: basal surface of the Axial Fan. NA (northern axis), CA (central axis) and SA (southern axis) point to the depositional axes visible at the base of the Fan. Vertical Exaggeration: $\mathrm{x} 50$. Location of cross-sections in Fig. 8.

Fig. 10: Growth pattern of the Axial Congo Fan. (A) Example of mainly prograding poplar-tree-like network of channels (A1: channels Ax01-13; A2: channels Ax45-52). (B) Example of an oak-tree-like prograding and laterally expanding network of channels (channels Ax20-44).

Fig. 11: Seismic facies of lobe Ax32. (A) 24 channels seismic cross-section. (B) Sub-bottom profiler (SPB) seismic cross-section. The lobe is topped by a small incised channel with thin lateral levees. On SBP data, the basal limits of the sedimentary units are not observable due to limited penetration, and come from the 24 channels seismic section. Vertical Exaggeration: x 19. Location of cross-sections in Fig. 7.

Fig. 12: Lobe clusters observed in the terminal lobes (lobes 1 to 3 or 4 , from the oldest to the youngest). Left: relief map; right: sketch of the lobes and their feeding channel. Black lines: youngest channels. Dashed lines: older channels, (A) Radial cluster of 3 lobes at the termination of channel Ax30, leading to the lateral spreading of the terminal lobe. (B) Progradational- cluster, type I, at the termination of the youngest channel of the Axial Fan (simplified from Babonneau, 2002): the channel keeps prograding by flowing around the preceding lobes. SL: Superficial lobe area (see section 4.2.3.2). (C) Progradational cluster, type II, at the 
termination of channel Ax32: the channel keeps prograding over its successive lobe sub-units. (D) Location of the maps $\mathrm{A}$ to $\mathrm{C}$.

Fig. 13: A ninety-six channel seismic cross-section showing the undifferentiated unit package 1 (UP1). Same vertical scale as profiles in Fig. 11. Vertical Exaggeration: x26. Location of this cross-section in Fig. 7.

Fig. 14: Width vs. maximum thickness for lobe-shaped morpho-acoustic objects identified at the termination of channels in the Congo Axial Fan, plotted on the log-log plot for depositional elements of different systems of Prélat et al. (2010).

Fig. 15: Diagram illustrating the correlation between the terminology (lobe and lobe complex from Prélat et al. (2010) adopted for the following sections of the paper and the objects described (units, sub-units, clusters) in the previous section 4.2 .

Fig. 16: Variability of lobe complex volume in the Congo Axial Fan. Colours correspond to groups of lobe complexes according to their volume. (A) Frequency distribution histrogram. The volumes are grouped into 3 main modes centered at 15,35 , and $55 \mathrm{~km}^{3}$ defining four main groups within which $22 \%$ are $<20 \mathrm{~km}^{3}, 22 \%$ range from 20 to $40 \mathrm{~km}^{3}, 4 \%$ range from 40 to $100 \mathrm{~km}^{3}$, and $15 \%$ are $>100 \mathrm{~km}^{3}$. (B) Cumulative frequency histogram. UPs are not considered in these plots. (C) Spatial distribution of the lobe complexes and UPs as a function of their volume.

Fig. 17: Length to width ratio (L/W) of the Axial Fan lobe complexes and UPs. (A) Frequency distribution showing main modes centered on 1.5 and 2.2. (B) Cumulative frequency histogram. Light grey, grey, and dark grey correspond to groups of lobe complexes according to their L/W ratio. (C) Plot of length (L) vs width (W) with indication of volume $(\mathrm{V}) . \mathrm{V}$ is imaged as colored circles, the surface of which is a function of the volume 
value. UPs are not considered in A and B, but are plotted on the graph C. (D) Spatial distribution of lobe complexes and UPs as a function of $\mathrm{L} / \mathrm{W}$.

Fig. 18: Temporal evolution of the architectural parameters. See Fig. 5 and section 4.4 for details concerning the method used. (1) Growth pattern of channel networks (see Fig. 10). (2) Sedimentary cycles defined by the prograding/retrograding movements of depocenters. (3) Number of avulsion points per channel. (4) Channel lengths diagram. (5) Avulsion points diagram. (6) Avulsion lengths diagram. Refer to section 3.4 and Fig. 5 for method used to construct these diagrams.

Fig. 19: Weak negative correlation $\left(R^{2}=0.4804\right)$ between the distances of the avulsion points $(D A)$ and the avulsion lengths on the new channel (AL).

Fig. 20: Temporal evolution of UPs and lobe complex volume and L/W ratio. (1) Channel length. A to $E$ refer to architectural cycles. (2) Lobe complex volume. (3) Lobe complex Length to Width ratios. See Fig. 18 for legends.

Fig. 21: Cross plot of lobe complex volume (V) vs channel Avulsion Length ( $A L)$ showing a large variability but where two main populations of lobe complexes are identifiable, (a) $60<\mathrm{V}<200 \mathrm{~km}^{3}$ associated to short AL ( $\leq$ $100 \mathrm{~km})$ and (b) $\mathrm{V}<60 \mathrm{~km}^{3}$ associated to variable $\mathrm{AL}(0<\mathrm{AL}<320 \mathrm{~km})$.

Fig. 22: Step by step architectural evolution of the Axial Fan ( $A$ to $D$ refers to architectural cycles). For simple description, cycle $C$ has been split into 2 stages $C 1$ and $C 2$. Left: Isochron map of the Axial Fan basement (see Fig.8A) showing the channels deposited at each cycle (red channels) and the previous channels (grey channels). Right: Line drawing (location on the maps to the left) of the depositional history of the different channels. Vertical Exaggeration: x50. Channels Ax01 and Ax19, located upstream from the cross-section are not visible here. Note that the deepening of the Southern Fan top surface is apparent and related to the 


\section{ACCEPTED MANUSCRIPT}

inadequate orientation of the cross-section with respect to the Southern Fan. Nevertheless, cross-section 1 in Fig. 9 indicates that, upfan, the Southern Fan was deeper than the Northern Fan at the time of Axial Fan initiation. The greyed area on the cross-sections indicates the portion of the profile that is not strictly transverse to the channels, especially those of the Southern Fan.

Fig. 23: Synthetic evolution through time and space of the architectural parameters of the Congo Axial Fan channel-lobe systems. (A) Schematic evolution of $\mathrm{DA}, \mathrm{CL}, \mathrm{AL}$, and $\mathrm{NbA}$ parameters. R: maxima of retrogradation; $\mathrm{P}$ : maxima of progradation of asymmetrical $(\mathrm{Pa})$ and bell-shaped $(\mathrm{Pb})$ cycles. $(\mathrm{B})$ Schematic characteristics of channels at the beginning $(\mathrm{R})$ and maxima of progradation $(\mathrm{Pa}$ and $\mathrm{Pb})$ of the asymmetrical and bell-shaped cycles. Successive channels are represented as different colors. Colored points are the avulsion points, associated to the newly created portion of channel (AL). DAf and ALf are final values of DA and AL. Red dots refer to secondary avulsion points resulting in the tree-like architecture and saw-tooth subcycles. Yellow ellipsoids figure lobe complexes at the channel terminations. Ref: Reference point.

Fig. 24: Upfan-downfan morphological evolution and morphological changes following an avulsion upfan (A) and downfan (B). (1) Conceptual cross-sections at the avulsions points. $\mathrm{HC}, \mathrm{H} 1$, and $\mathrm{H} 2$ are the current thickness and upfan and downfan levee heights, respectively. $\alpha 1$ and $\alpha 2$ are the slope gradient of the upfan and downfan levees, respectively ( $\alpha 1>\alpha 2$ ). (2) Conceptual dip sections (inspired from Pirmez et al., 2000) illustrating the severe morphological changes generated by avulsion in upfan regions and the low modifications in downfan domains.

Fig. 25: Factors controlling the sedimentary evolution of the Axial Fan as deduced from the evolution of the architectural parameters. Yellow lines refer to exceptional climatic or sea-level related events provoking upfan avulsions (as explained for the youngest event). DA: Distance of avulsion. AL: Avulsion length. TC: Turbidity currents. 


\section{TABLE CAPTIONS}

Table 1: Summary of used geophysical data and theoretical resolutions. MES: Multibeam Echo-Sounder.

Table 2: Equivalence table of channel labels between this study and that of Marsset et al. (2009). 


\section{LIST OF SUPPLEMENTARY MATERIAL}

A: Dimensions of lobes and UPs identified in the Congo Turbidite System.

${ }^{* *}$ : Mean thickness used for volume calculation. -: No lobe identified at the channel termination.

B: Dimensions of architectural parameters: DA, CL, AL, NbA (see text for explanation). 


\section{REFERENCES}

Alexander, J., Morris, S., 1994. Observations on Experimental, Non channelized, High-Concentration Turbidity Currents and Variations in Deposits Around Obstacles. J. Sediment. Res. 64.

Allen, P.A., Allen, J.R., 2013. Wiley: Basin Analysis: Principles and Application to Petroleum Play Assessment, 3rd Edition.

Amante, C., Eakins, B., 2008. Amante, C., \& Eakins, B. W. (2008). ETOPO1, 1 Arc-Minute Global Relief Model: Procedures, Data Sources and Analysis (NOAA Technical Memorandum). NESDIS NGDC-24. National Geophysical Data Center, NOAA. doi:10.7289/V5C8276M

Anka, Z., 2004. Evolution de l'éventail sous-marin du Zaïre (Congo) depuis le Crétacé: Interaction avec la marge continentale du golfe de Guinée (PhD thesis). Université de Montpellier 2.

Anka, Z., Séranne, M., Primio, R. di, 2010. Evidence of a large upper-Cretaceous depocentre across the Continent-Ocean boundary of the Congo-Angola basin. Implications for palaeo-drainage and potential ultra-deep source rocks. Mar. Pet. Geol. 27, 601-611. doi:10.1016/j.marpetgeo.2009.08.015

Armitage, D.A., McHargue, T., Fildani, A., Graham, S.A., 2012. Postavulsion channel evolution: Niger Delta continental slope. AAPG Bull. 96, 823-843. doi:10.1306/09131110189

Babonneau, N., 2002. Mode de fonctionnement d'un chenal turbiditique méandriforme: Cas du Système Turbiditique Actuel du Zaïre (PhD thesis). Université de Bordeaux I.

Babonneau, N., Savoye, B., Cremer, M., Bez, M., 2004. Multiple terraces within the deep incised Zaire Valley (ZaïAngo Project): are they confined levees? Geol. Soc. Lond. Spec. Publ. 222, 91-114. doi:10.1144/GSL.SP.2004.222.01.06

Babonneau, N., Savoye, B., Cremer, M., Klein, B., 2002. Morphology and architecture of the present canyon and channel system of the Zaire deep-sea fan. Mar. Pet. Geol. 19, 445-467. doi:10.1016/S02648172(02)00009-0

Babonneau, N., Savoye, B., Droz, L., Morash, A., Bez, M., 2005. Large Modern Deep-Sea Fans: The Amazon Channel Versus the Zaire Channel, in: 2005 AAPG Annual Convention. pp. 19-22.

Badalini, G., Kneller, B., Winker, C.D., 2000. Architecture and processes in the late Pleistocene Brazos-Trinity turbidite system, Gulf of Mexico continental slope, in: Deep-Water Reservoirs of the World: SEPM, Gulf Coast Section, 20th Annual Research Conference. SEPM, pp. 16-34.

Bonneau, L., Jorry, S.J., Toucanne, S., Silva Jacinto, R., Emmanuel, L., 2014. Millennial-Scale Response of a Western Mediterranean River to Late Quaternary Climate Changes: A View from the Deep Sea. J. Geol. 122, 687-703. doi:10.1086/677844

Bonnel, C., 2005. Mise en place des lobes distaux dans les systèmes turbiditiques actuels: analyse comparée des systèmes du Zaïre, Var, et Rhône (PhD thesis). Université de Bordeaux 1.

Bouma, A.H., Coleman, J.M., Scientists, D.L. 96 S., 1985. Mississippi Fan: Leg 96 Program and Principal Results, in: Bouma, A.H., Normark, W.R., Barnes, N.E. (Eds.), Submarine Fans and Related Turbidite Systems, Frontiers in Sedimentary Geology. Springer New York, pp. 247-252.

Brice, S.E., Cochran, M.D., Pardo, G., Edwards, A.D., 1982. Tectonics and sedimentation of the South Atlantic rift sequence: Cabinda, Angola. Stud. Cont. Margin Geol. AAPG Mem. 34, 5-18.

Cochonat, P., 1998. ZAIANGO2 cruise, L'Atalante R/V. doi:10.17600/98010110

Cochonat, P., Robin, A., 1992. GUINESS I cruise, L'Atalante R/V. doi:10.17600/92004211

Curray, J.R., Moore, D.G., 1971. Growth of the Bengal Deep-Sea Fan and Denudation in the Himalayas. Geol. Soc. Am. Bull. 82, 563-572. doi:10.1130/0016-7606(1971)82[563:GOTBDF]2.0.CO;2

Damuth, J.E., Flood, R.D., 1983. Morphology, sedimentation processes, and growth pattern of the Amazon Deep-Sea Fan. Geo-Mar. Lett. 3, 109-117. doi:10.1007/BF02462455

Dennielou, B., Jouanneau, J.-M., Marsset, T., Droz, L., Savoye, B., Migeon, S., Lopez, M., Suc, J.-P., Volat, J.L., 2003. Age Control on the Zaire Deep-Sea Fan: From 100 ka to Decadal Scale, in: AAPG Annual Meeting 2003.

Devroey, E., 1941. Le bassin hydrographique congolais: spécialement celui du bief maritime. G. van Campenhout.

Dorrell, R.M., Burns, A.D., McCaffrey, W.D., 2015. The inherent instability of leveed seafloor channels. Geophys. Res. Lett. 42, 2015GL063809. doi:10.1002/2015GL063809 
Droz, L., Marsset, T., 2011. REPREZAI_LEG2 cruise, Le Suroît R/V,. doi:10.17600/11020020

Droz, L., Marsset, T., Ondréas, H., Lopez, M., Savoye, B., Spy-Anderson, F.-L., 2003. Architecture of an active mud-rich turbidite system: The Zaire Fan (Congo-Angola margin southeast Atlantic) Results from ZaïAngo 1 and 2 cruises. AAPG Bull. 87, 1145-1168. doi:10.1306/03070300013

Droz, L., Rigaut, F., Cochonat, P., Tofani, R., 1996. Morphology and recent evolution of the Zaire turbidite system (Gulf of Guinea). Geol. Soc. Am. Bull. 108, 253-269. doi:10.1130/00167606(1996)108<0253:MAREOT>2.3.CO;2

Emery, K.O., Uchupi, E., Phillips, J., Bowin, C., Mascle, J., 1975. Continental Margin Off Western Africa: Angola to Sierra Leone. AAPG Bull. 59, 2209-2265.

Flood, R.D., Manley, P.L., Kowsmann, R.O., Appi, C.J., Pirmez, C., 1991. Seismic Facies and Late Quaternary Growth of Amazon Submarine Fan, in: Weimer, P., Link, M.H. (Eds.), Seismic Facies and Sedimentary Processes of Submarine Fans and Turbidite Systems, Frontiers in Sedimentary Geology. Springer New York, pp. 415-433.

Flood, R.D., Piper, D.J.W., 1997. Amazon fan sedimentation: The relationship to equatorial climate change, continental denudation, and sea-level fluctuations. Proc. Ocean Drill. Program Sci. Results 155, 653675.

Gladstone, Phillips, Sparks, 1998. Experiments on bidisperse, constant-volume gravity currents: propagation and sediment deposition. Sedimentology 45, 833-843. doi:10.1046/j.1365-3091.1998.00189.x

Heezen, B.C., Menzies, R.J., Schneider, E.D., Ewing, W.M., Granelli, N.C.L., 1964. Congo Submarine Canyon. AAPG Bull. 48, 1126-1149.

Hjulstrom, F., 1939. Transportation of Detritus by Moving Water: Part 1. Transportation 142, 5-31.

Hodgson, D.M., Flint, S.S., Hodgetts, D., Drinkwater, N.J., Johannessen, E.P., Luthi, S.M., 2006. Stratigraphic Evolution of Fine-Grained Submarine Fan Systems, Tanqua Depocenter, Karoo Basin, South Africa. J. Sediment. Res. 76, 20-40. doi:10.2110/jsr.2006.03

Jansen, J., 1985. Hiatuses in Mesozoic and Cenozoic sediments of the Zaire (Congo) continental shelf, slope, and deep-sea fan. South Atl. Paleoceanogr. Eds KJ Hsu HJ Weissert 197-204.

Jégou, I., 2008. Etude de la transition chenal-levées/lobe dans les systèmes turbiditiques récents. Application à l'éventail turbiditique de l'Amazone et au Néofan du Petit-Rhône (PhD thesis). Université de Bretagne Occidentale, Brest.

Jegou, I., Savoye, B., Pirmez, C., Droz, L., 2008. Channel-mouth lobe complex of the recent Amazon Fan: The missing piece. Mar. Geol. 252, 62-77. doi:10.1016/j.margeo.2008.03.004

Jorry, S.J., Jégou, I., Emmanuel, L., Silva Jacinto, R., Savoye, B., 2011. Turbiditic levee deposition in response to climate changes: The Var Sedimentary Ridge (Ligurian Sea). Mar. Geol. 279, 148-161. doi:10.1016/j.margeo.2010.10.021

Karner, G.D., Driscoll, N.W., 1999. Tectonic and stratigraphic development of the West African and eastern Brazilian Margins: insights from quantitative basin modelling. Geol. Soc. Lond. Spec. Publ. 153, 11-40. doi:10.1144/GSL.SP.1999.153.01.02

Khripounoff, A., Vangriesheim, A., Babonneau, N., Crassous, P., Dennielou, B., Savoye, B., 2003. Direct observation of intense turbidity current activity in the Zaire submarine valley at $4000 \mathrm{~m}$ water depth. Mar. Geol. 194, 151-158. doi:10.1016/S0025-3227(02)00677-1

Kinga-Mouzeo, 1986. Transport particulaire actuel du fleuve Congo et de quelques affluents; enregistrement quaternaire dans l'éventail détritique profond (sédimentologie, minéralogie et géochimie) (PhD thesis). Université de Perpignan.

Kneller, B., 2003. The influence of flow parameters on turbidite slope channel architecture. Mar. Pet. Geol. 20, 901-910. doi:10.1016/j.marpetgeo.2003.03.001

Kneller, B., 1995. Beyond the turbidite paradigm: physical models for deposition of turbidites and their implications for reservoir prediction. Geol. Soc. Lond. Spec. Publ. 94, 31-49. doi:10.1144/GSL.SP.1995.094.01.04

Kneller, B., McCaffrey, W., 1999. Depositional Effects of Flow Nonuniformity and Stratification Within Turbidity Currents Approaching a Bounding Slope: Deflection, Reflection, and Facies Variation. J. Sediment. Res. 69. 
Kolla, V., 2007. A review of sinuous channel avulsion patterns in some major deep-sea fans and factors controlling them. Mar. Pet. Geol., Sinuous Deep-Water Channels: Genesis, Geometry and Architecture Sinuous Deep-Water Channels 24, 450-469. doi:10.1016/j.marpetgeo.2007.01.004

Kolla, V., Coumes, F., 1987. Morphology, Internal Structure, Seismic Stratigraphy, and Sedimentation of Indus Fan. AAPG Bull. 71, 650-677.

Kolla, V., Macurda Jr, D., 1988. Sea-level changes and timing of turbidity-current events in deep-sea fan systems in Wilgus, CK, Hastings, BS, Kendall,.., CG, St., C., Posamentier, HW, Ross, CA, Van Wagoner, JC (Eds.), Sea-level Changes e An Integrated Approach. SEPM Special Publication, 1988, vol. 42 , p. 381e392.

Lopez, M., 2001. Architecture and depositional pattern of the Quaternary deep-sea fan of the Amazon. Mar. Pet. Geol. 18, 479-486. doi:10.1016/S0264-8172(00)00071-4

Manley, P.L., Flood, R.D., 1988. Cyclic Sediment Deposition Within Amazon Deep-Sea Fan. AAPG Bull. 72, 912-925.

Marsset, T., Droz, L., 2010. REPREZAI_LEG1 cruise, Pourquoi Pas? R/V. doi:10.17600/10030170

Marsset, T., Droz, L., Dennielou, B., Pichon, E., 2009. Cycles in the architecture of the Quaternary Zaïre turbidite system: a possible link with climate. Extern. Controls Deep-Water Depositional Syst. 89-106.

Maslin, M., Knutz, P.C., Ramsay, T., 2006. Millennial-scale sea-level control on avulsion events on the Amazon Fan. Quat. Sci. Rev. 25, 3338-3345. doi:10.1016/j.quascirev.2006.10.012

McCaffrey, W.D., Kneller, B.C., 2004. Scale effects of non-uniformity on deposition from turbidity currents with reference to the Grès d'Annot of SE France. Geol. Soc. Lond. Spec. Publ. 221, 301-310. doi:10.1144/GSL.SP.2004.221.01.16

Moguedet, G., 1988. Les relations entre le fleuve congo et la sedimentation recente sur la marge continentale entre l'embouchure et le sud du gabon: etude hydrologique, sedimentologique et geochimique (PhD thesis). Université d'Angers.

Morris, E.A., Hodgson, D.M., Flint, S.S., Brunt, R.L., Butterworth, P.J., Verhaeghe, J., 2014. Sedimentology, Stratigraphic Architecture, and Depositional Context of Submarine Frontal-Lobe Complexes. J. Sediment. Res. 84, 763-780. doi:10.2110/jsr.2014.61

Mutti, E., Ricci Lucchi, F., 1972. Le torbiditi dell'Appennino settentrionale: introduzione all'analisi di facies. Mem. Della Soc. Geol. Ital. 11, 161-199.

Ortiz-Karpf, A., Hodgson, D.M., McCaffrey, W.D., 2015. The role of mass-transport complexes in controlling channel avulsion and the subsequent sediment dispersal patterns on an active margin: The Magdalena Fan, offshore Colombia. Mar. Pet. Geol. 64, 58-75. doi:10.1016/j.marpetgeo.2015.01.005

Payros, A., Martínez-Braceras, N., 2014. Orbital forcing in turbidite accumulation during the Eocene greenhouse interval. Sedimentology 61,1411-1432. doi:10.1111/sed.12113

Pirmez, C., Beaubouef, R., Friedmann, S., Mohrig, D., 2000. Equilibrium profile and baselevel in submarine channels: examples from Late Pleistocene systems and implications for the architecture of deepwater reservoirs, in: Global Deep-Water Reservoirs: Gulf Coast Section SEPM Foundation 20th Annual Bob F. Perkins Research Conference. SEPM, pp. 782-805.

Pirmez, C., Hiscott, R.N., Kronen, J.D., 1997. Sandy turbidite successions at the base of channel-levee systems of the amazon fan revealed by FMS logs and cores: Unraveling the facies architecture of large submarine fans. Proc. Ocean Drill. Program Sci. Results 155, 7-33.

Pirmez, C., Imran, J., 2003. Reconstruction of turbidity currents in Amazon Channel. Mar. Pet. Geol., Turbidites: Models and Problems 20, 823-849. doi:10.1016/j.marpetgeo.2003.03.005

Prélat, A., Covault, J.A., Hodgson, D.M., Fildani, A., Flint, S.S., 2010. Intrinsic controls on the range of volumes, morphologies, and dimensions of submarine lobes. Sediment. Geol. 232, 66-76. doi:10.1016/j.sedgeo.2010.09.010

Prélat, A., Hodgson, D.M., Flint, S.S., 2009. Evolution, architecture and hierarchy of distributary deep-water deposits: a high-resolution outcrop investigation from the Permian Karoo Basin, South Africa. Sedimentology 56, 2132-2154. doi:10.1111/j.1365-3091.2009.01073.x

Reading, H.G., Richards, M., 1994. Turbidite Systems in Deep-Water Basin Margins Classified by Grain Size and Feeder System. AAPG Bull. 78, 792-822.

Reyre, D., 1984. Caractères pétroliers et évolution géologique d'une marge passive. Le cas du bassin Bas Congo-Gabon. Bull. Centres Rech. Explor.-Prod. Elf Aquitaine 8, 303-332. 
Rigaut, F., 1997. Analyse et évolution récente d'un système turbiditique méandriforme: l'éventail profond du Zaïre (PhD thesis). Université de Bretagne Occidentale, Brest.

Salaheldin, T.M., Imran, J., Chaudhry, M.H., Reed, C., 2000. Role of fine-grained sediment in turbidity current flow dynamics and resulting deposits. Mar. Geol. 171, 21-38. doi:10.1016/S0025-3227(00)00114-6

Savoye, B., 1998. ZAIANGO1 cruise, L'Atalante R/V. doi:10.17600/98010100

Savoye, B., Babonneau, N., Dennielou, B., Bez, M., 2009. Geological overview of the Angola-Congo margin, the Congo deep-sea fan and its submarine valleys. Deep Sea Res. Part II Top. Stud. Oceanogr. 56, 2169-2182. doi:10.1016/j.dsr2.2009.04.001

Savoye, B., Cochonat, P., Apprioual, R., Bain, O., Baltzer, A., Bellec, V., Beuzart, P., Bourillet, J.-F., Cagna, R., Cremer, M., Crusson, A., Dennielou, B., Diebler, D., Droz, L., Ennes, J.-C., Floch, G., Guiomar, M., Harmegnies, F., Kerbrat, R., Klein, B., Kuhn, H., Landuré, J.-Y., Lasnier, C., Le Drezen, E., Le Formal, J.-P., Lopez, M., Loubrieu, B., Marsset, T., Migeon, S., Normand, A., Nouzé, H., Ondréas, H., Pelleau, P., Saget, P., Séranne, M., Sibuet, J.-C., Tofani, R., Voisset, M., 2000. Structure et évolution récente de l'éventail turbiditique du Zaïre : premiers résultats scientifiques des missions d'exploration Zaïango1 \& 2 (marge Congo-Angola). Comptes Rendus Académie Sci. - Ser. IIA - Earth Planet. Sci. 331, 211220. doi:10.1016/S1251-8050(00)01385-9

Stow, D.A.V., Mayall, M., 2000. Deep-water sedimentary systems: New models for the 21st century. Mar. Pet. Geol. 17, 125-135. doi:10.1016/S0264-8172(99)00064-1

Stow, D.A.V., Reading, H.G., Collinson, J.D., 1996. Deep Seas in Sedimentary Environments. Process. Facies Stratigr. Blakwell Sci. 395-454.

Toucanne, S., Zaragosi, S., Bourillet, J.-F., Dennielou, B., Jorry, S.J., Jouet, G., Cremer, M., 2012. External controls on turbidite sedimentation on the glacially-influenced Armorican margin (Bay of Biscay, western European margin). Mar. Geol. 303-306, 137-153. doi:10.1016/j.margeo.2012.02.008

Turakiewicz, G., 2004. Les mécanismes forçants dans les éventails turbiditiques de marges matures : exemple de l'éventail quaternaire du Congo (PhD thesis). Université de Montpellier 2.

Twichell, D.C., Schwab, W.C., Kenyon, N.H., Lee, H.J., 1996. Breaching the levee of a channel on the Mississippi Fan. Geol. U. S. Seapounds Oor View GLORIA Camb. Univ. Press Camb. UK 85-96.

Van der Merwe, W.C., Hodgson, D.M., Brunt, R.L., Flint, S.S., 2014. Depositional architecture of sandattached and sand-detached channel-lobe transition zones on an exhumed stepped slope mapped over a 2500 km2 area. Geosphere GES01035.1. doi:10.1130/GES01035.1

Van Weering, T.C.E., Van Iperen, J., 1984. Fine-grained sediments of the Zaire deep-sea fan, southern Atlantic Ocean. Geol. Soc. Lond. Spec. Publ. 15, 95-113. doi:10.1144/GSL.SP.1984.015.01.06

Wefer, G., Berger, W.H., Richter, C., et al., 1998a. Proceedings of the Ocean Drilling Program 175 Initial Reports, Proceedings of the Ocean Drilling Program. Ocean Drilling Program.

Wefer, G., Berger, W.H., Richter, C., et al., 1998b. Shipboard Scientific Party, Site 1077, in: Proceedings of the Ocean Drilling Program 175 Initial Reports, Proceedings of the Ocean Drilling Program. 


\section{SUPPLEMENTARY MATERIAL}

\begin{tabular}{|c|c|c|c|c|c|c|c|}
\hline Lobes & $\begin{array}{l}\text { Length } \\
(\mathrm{km})\end{array}$ & $\begin{array}{l}\text { Width } \\
(\mathrm{km})\end{array}$ & $\begin{array}{l}\mathrm{L} / \mathrm{W} \\
\text { Ratio }\end{array}$ & $\begin{array}{c}\text { Max } \\
\text { Thickness } \\
\text { (std) }\end{array}$ & $\begin{array}{c}\text { Max } \\
\text { Thickness } \\
(\mathrm{m})\end{array}$ & $\begin{array}{c}\text { Surface } \\
\text { area }\left(\mathrm{km}^{2}\right)\end{array}$ & $\begin{array}{c}\text { Volume } \\
\text { (km3) }\end{array}$ \\
\hline $\mathrm{Ax01}$ & 26 & 14 & 1.86 & 0.14 & 109 & 297 & 21 \\
\hline Ax02 & 25 & 16 & 1.56 & 0.13 & 101 & 302 & 21 \\
\hline Ax03 & - & - & - & - & - & - & - \\
\hline $\mathrm{Ax04}$ & 32 & 22 & 1.45 & 0.137 & 106 & 566 & 39 \\
\hline $\mathrm{Ax} 05$ & 33 & 20 & 1.65 & 0.126 & 98 & 495 & 34 \\
\hline $\mathrm{A} \times 06$ & 89 & 35 & 2.54 & 0.155 & 120 & 2649 & 196 \\
\hline $\mathrm{A} \times 07$ & 57 & 28 & 2.04 & 0.171 & 133 & 1497 & 111 \\
\hline $\mathrm{Ax08}$ & 38 & 18 & 2.11 & 0.128 & 99 & 544 & 36 \\
\hline Ax09 & 60 & 15 & 4.00 & 0.031 & 23 & 753 & 11 \\
\hline$A \times 10$ & 98 & 42 & 2.33 & 0.081 & 63 & 2901 & 135 \\
\hline$A \times 11$ & 30 & 22 & 1.36 & 0.12 & 93 & 572 & 32 \\
\hline$A \times 12$ & - & - & - & - & - & - & - \\
\hline$A \times 13$ & 47 & 39 & 1.21 & 0.117 & 91 & 1532 & 87 \\
\hline$A \times 14$ & 45 & 30 & 1.50 & 0.1 & 68 & 792.0 & 48 \\
\hline$A \times 15$ & - & - & - & - & - & - & - \\
\hline Ax16 & - & - & - & - & - & - & - \\
\hline$A \times 17$ & 38 & 29 & 1.31 & 0.13 & 101 & 872 & 58 \\
\hline Ax18 & 46 & 21 & 2.20 & 0.11 & 85 & 799 & 43 \\
\hline$A \times 19$ & 80 & 18 & 4.44 & 0.12 & 93 & 949 & 70 \\
\hline$A \times 20$ & 45 & 28 & 1.61 & 0.073 & 57 & 1090 & 37 \\
\hline UP1 & 138 & 51 & 2.71 & 0.223 & 173 & 5824 & 637 \\
\hline$A \times 21$ & - & - & - & - & - & - & - \\
\hline$A \times 22$ & 72 & 32 & 2.30 & 0.112 & 87 & 1706 & 105 \\
\hline$A \times 23$ & 56 & 16 & 3.50 & 0.112 & 87 & 723 & 41 \\
\hline$A \times 24$ & 17 & 8 & 2.13 & 0.048 & 37 & 116 & 3 \\
\hline$A \times 25$ & 48 & 30 & 1.60 & 0.106 & 82 & 1183 & 62 \\
\hline$A \times 26$ & 36 & 28 & 1.29 & 0.128 & 99 & 678 & 52 \\
\hline$A \times 27$ & 42 & 16 & 2.63 & 0.1 & 43 & 623 & 15 \\
\hline$A \times 28$ & 58 & 29 & 2.00 & 0.106 & 82 & 1424 & 72 \\
\hline Ax29 & 25 & 15 & 1.67 & 0.075 & 58 & 301 & 11 \\
\hline$A \times 30$ & 56 & 45 & 1.20 & 0.115 & 89 & 1900 & 118 \\
\hline$A \times 31$ & 38 & 30 & 1.27 & 0.13 & 101 & 1066 & 60 \\
\hline$A \times 32$ & 56 & 17 & 3.30 & 0.118 & 91 & 960 & 46 \\
\hline Ax33 & 80 & 26 & 3.08 & 0.106 & 82 & 1325 & 89 \\
\hline$A \times 34$ & 36 & 31 & 1.16 & 0.088 & 68 & 885 & 40 \\
\hline$A \times 35$ & - & - & - & - & - & - & - \\
\hline UP2 & 98 & 58 & 1.69 & 0.254 & 197 & 4173 & 586 \\
\hline Ax36 & 45 & 31 & 1.45 & 0.108 & 84 & 1163 & 61 \\
\hline$A \times 37$ & 54 & 18 & 3.00 & 0.162 & 126 & 824 & 64 \\
\hline$A \times 38$ & 40 & 26 & 1.54 & 0.041 & 30 & 790 & 17 \\
\hline Ax39 & 40 & 17 & 2.35 & 0.058 & 45 & 577 & 16 \\
\hline $\mathrm{A} \times 40$ & 17 & 12 & 1.42 & 0.069 & 53 & 146 & 6 \\
\hline$A \times 41$ & 42 & 21 & 2.00 & 0.1 & 78 & 678 & 36 \\
\hline$A \times 42$ & 33 & 27 & 1.22 & 0.157 & 122 & 732 & 57 \\
\hline$A \times 43$ & 44 & 18 & 2.40 & 0.063 & 49 & 683 & 20 \\
\hline$A \times 44$ & 61 & 43 & 1.42 & 0.145 & 112 & 2085 & 154 \\
\hline$A \times 45$ & 90 & 36 & 2.50 & 0.04 & 30 & 2136 & 50 \\
\hline$A \times 46$ & 19 & 13 & 1.46 & 0.111 & 86 & 206 & 11 \\
\hline Ax47 & 48 & 22 & 2.18 & 0.14 & 109 & 916 & 60 \\
\hline Ax48 & 34 & 22 & 1.55 & 0.064 & 50 & 613 & 19 \\
\hline Ax49 & 26 & 19 & 1.37 & 0.06 & 47 & 388 & 12 \\
\hline$A \times 50$ & 200 & 60 & 3.33 & $0.04^{* *}$ & 30 & 9177 & $186^{\star *}$ \\
\hline$A \times 51$ & 65 & 27 & 2.40 & 0.104 & 81 & 1181 & 74 \\
\hline$A \times 52$ & 97 & 31 & 3.10 & 0.074 & 57 & 1808 & 90 \\
\hline
\end{tabular}

Supplementary Material A: Dimensions of lobes and UPs identified in the Congo Turbidite System.

**: Mean thickness used for volume calculation. -: No lobe identified at the channel termination. 


\begin{tabular}{|c|c|c|c|c|c|}
\hline Channel & $\mathrm{CL}(\mathrm{km})$ & $\mathrm{NbA}$ & Avulsion & $\mathrm{DA}(\mathrm{km})$ & $\mathrm{AL}(\mathrm{km})$ \\
\hline $\mathrm{Ax01}$ & 324 & & & & \\
\hline $\mathrm{Ax} 02$ & 509 & 1 & 01/02 & 223 & 286 \\
\hline $\mathrm{Ax03}$ & 680 & 1 & 02/03 & 213 & 468 \\
\hline $\mathrm{Ax04}$ & 651 & 2 & 03/04 & 604 & 48 \\
\hline $\mathrm{A} \times 05$ & 772 & 2 & $04 / 05$ & 573 & 199 \\
\hline Ax06 & 783 & 3 & 05/06 & 760 & 23 \\
\hline $\mathrm{A} \times 07$ & 728 & 3 & 06/07 & 716 & 12 \\
\hline $\mathrm{Ax08}$ & 737 & 3 & 07/08 & 689 & 48 \\
\hline Ax09 & 894 & 4 & 08/09 & 737 & 157 \\
\hline$A \times 10$ & 963 & 5 & $09 / 10$ & 894 & 69 \\
\hline$A \times 11$ & 1066 & 6 & $10 / 11$ & 957 & 109 \\
\hline$A \times 12$ & 1112 & 7 & $11 / 12$ & 1066 & 46 \\
\hline$A \times 13$ & 542 & 2 & $12 / 13$ & 542 & 0 \\
\hline$A \times 14$ & 516 & 2 & $13 / 14$ & 280 & 236 \\
\hline$A \times 15$ & 572 & 3 & $14 / 15$ & 468 & 104 \\
\hline$A \times 16$ & 563 & 4 & $15 / 16$ & 543 & 20 \\
\hline$A \times 17$ & 634 & 5 & $16 / 17$ & 543 & 92 \\
\hline$A \times 18$ & 640 & 6 & $17 / 18$ & 611 & 29 \\
\hline$A \times 19$ & 293 & 1 & $18 / 19$ & 205 & 88 \\
\hline Ax20 & 488 & 1 & $19 / 20$ & 174 & 315 \\
\hline UP1 & 362 & - & 20/UP1 & - & - \\
\hline$A \times 21$ & 531 & 2 & UP1/21 & 298 & 234 \\
\hline$A \times 22$ & 463 & 3 & $21 / 22$ & 426 & 37 \\
\hline Ax23 & 409 & 2 & $22 / 23$ & 300 & 109 \\
\hline$A \times 24$ & 548 & 3 & $23 / 24$ & 409 & 139 \\
\hline$A \times 25$ & 641 & 4 & $24 / 25$ & 506 & 135 \\
\hline$A \times 26$ & 751 & 5 & $25 / 26$ & 641 & 110 \\
\hline$A \times 27$ & 671 & 4 & $26 / 27$ & 640 & 31 \\
\hline Ax28 & 781 & 4 & $27 / 28$ & 506 & 275 \\
\hline Ax29 & 852 & 5 & $28 / 29$ & 768 & 84 \\
\hline$A \times 30$ & 893 & 6 & $29 / 30$ & 809 & 84 \\
\hline$A \times 31$ & 874 & 7 & $30 / 31$ & 841 & 34 \\
\hline$A \times 32$ & 834 & 5 & $31 / 32$ & 763 & 71 \\
\hline$A \times 33$ & 829 & 6 & $32 / 33$ & 829 & 0 \\
\hline Ax34 & 740 & 5 & $33 / 34$ & 740 & 0 \\
\hline Ax35 & 775 & 6 & $34 / 35$ & 740 & 35 \\
\hline UP2 & 600 & - & 33/UP2 & - & - \\
\hline$A \times 36$ & 702 & 5 & UP2/36 & 591 & 112 \\
\hline$A \times 37$ & 755 & 6 & $36 / 37$ & 689 & 66 \\
\hline$A \times 38$ & 760 & 7 & $37 / 38$ & 731 & 29 \\
\hline Ax39 & 582 & 5 & $38 / 39$ & 582 & 0 \\
\hline$A \times 40$ & 555 & 5 & $39 / 40$ & 555 & 0 \\
\hline Ax41 & 598 & 5 & $40 / 41$ & 555 & 43 \\
\hline$A \times 42$ & 619 & 4 & $41 / 42$ & 476 & 143 \\
\hline$A \times 43$ & 635 & 5 & $42 / 43$ & 579 & 57 \\
\hline $\mathrm{A} \times 44$ & 719 & 6 & $43 / 44$ & 635 & 84 \\
\hline$A \times 45$ & 404 & 2 & $44 / 45$ & 185 & 219 \\
\hline$A \times 46$ & 535 & 3 & $45 / 46$ & 388 & 147 \\
\hline Ax47 & 662 & 4 & $46 / 47$ & 493 & 169 \\
\hline$A \times 48$ & 640 & 5 & $47 / 48$ & 580 & 60 \\
\hline Ax49 & 658 & 6 & $48 / 49$ & 629 & 29 \\
\hline$A \times 50$ & 724 & 7 & $49 / 50$ & 638 & 86 \\
\hline Ax51 & 683 & 6 & $50 / 51$ & 683 & 0 \\
\hline Ax52 & 784 & 7 & $51 / 52$ & 683 & 101 \\
\hline
\end{tabular}

Supplementary Material B: Dimensions of architectural parameters: $D A, C L, A L, N b A$ (see text for explanation). 